\title{
Neuronal Heterotopias Affect the Activities of Distant Brain Areas and Lead to Behavioral Deficits
}

\author{
- Kazuhiro Ishii, ${ }^{1 *}$ - Ken-ichiro Kubo, ${ }^{1 \star}$ Toshihiro Endo, ${ }^{2,3}$ Keitaro Yoshida, ${ }^{4}$ Seico Benner, ${ }^{2}$ Yukiko Ito, ${ }^{5}$ \\ (Hidenori Aizawa, ${ }^{5,6}$ Michihiko Aramaki, ${ }^{1}{ }^{\circledR}$ Akihiro Yamanaka, ${ }^{7}$ Kohichi Tanaka, ${ }^{5,8}$ Norio Takata, ${ }^{4}$ Kenji F. Tanaka, ${ }^{4}$ \\ Masaru Mimura, ${ }^{4}$ Chiharu Tohyama, ${ }^{2}{ }^{-}$Masaki Kakeyama, ${ }^{2,9}$ and Kazunori Nakajima ${ }^{1}$ \\ ${ }^{1}$ Department of Anatomy, Keio University School of Medicine, Tokyo, 160-8582, Japan, ${ }^{2}$ Laboratory of Environmental Health Sciences, Center for Disease \\ Biology and Integrative Medicine, Graduate School of Medicine, and ${ }^{3}$ Department of Neurochemistry, Graduate School of Medicine, University of Tokyo, \\ Tokyo, 113-0033, Japan, ${ }^{4}$ Department of Neuropsychiatry, Keio University School of Medicine, Tokyo, 160-8582, Japan, ${ }^{5}$ Laboratory of Molecular \\ Neuroscience, Medical Research Institute, Tokyo Medical and Dental University, Tokyo, 113-8510, Japan, ${ }^{6}$ Department of Neurobiology, Institute of \\ Biomedical and Health Sciences, Hiroshima University, Hiroshima, 734-8553, Japan, ${ }^{7}$ Department of Neuroscience II, Research Institute of Environmental \\ Medicine, Nagoya University, Nagoya, 464-8601, Japan, ${ }^{8}$ Center for Brain Integration Research, Tokyo Medical and Dental University, Tokyo, 113-8510,

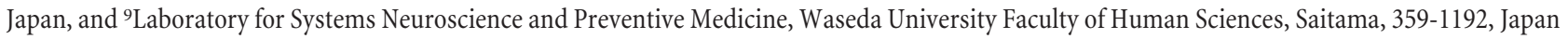

Neuronal heterotopia refers to brain malformations resulting from deficits of neuronal migration. Individuals with heterotopias show a high incidence of neurological deficits, such as epilepsy. More recently, it has come to be recognized that focal heterotopias may also show a range of psychiatric problems, including cognitive and behavioral impairments. However, because focal heterotopias are not always located in the brain areas responsible for the symptoms, the causal relationship between the symptoms and heterotopias remains elusive. In this study, we showed that mice with focal heterotopias in the somatosensory cortex generated by in utero electroporation exhibited spatial working memory deficit and low competitive dominance behavior, which have been shown to be closely associated with the activity of the medial prefrontal cortex (mPFC) in rodents. Analysis of the MPFC activity revealed that the immediate-early gene expression was decreased and the local field potentials of the $\mathrm{MPFC}$ were altered in the mice with heterotopias compared with the control mice. Moreover, activation of these ectopic and overlying sister neurons using the DREADD (designer receptor exclusively activated by designer drug) system improved the working memory deficits. These findings suggest that cortical regions containing focal heterotopias can affect distant brain regions and give rise to behavioral abnormalities.

Key words: DREADD; heterotopia; in utero electroporation; IntelliCage; neuropsychiatric symptom; optogenetics

Significance Statement

Recent studies reported that patients with heterotopias have a variety of clinical symptoms, such as cognitive disturbance, psychiatric symptoms, and autistic behavior. However, the causal relationship between the symptoms and heterotopias remains elusive. Here we showed that mice with focal heterotopias in the somatosensory cortex generated by in utero electroporation exhibited behavioral deficits that have been shown to be associated with the MPFC activity in rodents. The existence of heterotopias indeed altered the neural activities of the MPFC, and direct manipulation of the neural activity of the ectopic neurons and their sister neurons in the overlying cortex improved the behavioral deficit. Thus, our results indicate that focal heterotopias could affect the activities of distant brain areas and cause behavioral abnormalities.

\section{Introduction}

Neuronal heterotopias are caused by impairment of the processes underlying brain ontogenesis, especially of neuronal migration, and most are closely related to genetic disruption (Ekşioğlu et al., 1996; Clark, 2004; Sisodiya, 2004). Individuals with these malformations commonly show a high incidence of neurological deficits, such as epilepsy and mental retardation (Dobyns et al., 1996; 
Gleeson et al., 1998; Aghakhani et al., 2005; Manent et al., 2009). As exemplified by patients with periventricular nodular heterotopia, it has come to be recognized that individuals with focal heterotopias show cognitive and behavioral impairments, and a range of psychiatric problems as well as epilepsy and intellectual disabilities (Chang et al., 2005; Felker et al., 2011; Fry et al., 2013). Moreover, autistic behavior and attention-deficit/hyperactivity disorder have also been reported in patients with focal heterotopias (Nopoulos et al., 2000; Wegiel et al., 2010). These suggest the possible association of heterotopias with a variety of symptoms. However, the causal relationship of focal heterotopias to the neuropsychiatric symptoms and behavioral problems is still unclear. Dysfunction in the prefrontal cortex (PFC), which plays important roles in cognitive functions and social behavior, has been implicated in many psychiatric diseases (Weinberger et al., 1988; Amodio and Frith, 2006). On the other hand, the heterotopias associated with neuropsychiatric symptoms are not always located in the PFC but in various regions of the brain (Fry et al., 2013). These findings suggest the possibility that focal heterotopias could secondarily affect the activity of other brain regions, including that of the PFC. However, the neurological mechanism underlying this has not yet been vigorously addressed.

To examine this issue, we generated multiple mouse models of focal heterotopias and investigated their behaviors in this study. To produce heterotopias in the somatosensory cortex, we ectopically overexpressed one of the following three molecules by in utero electroporation (Tabata and Nakajima, 2001; Kubo et al., 2010): (1) Reelin, a protein involved in laminar formation and neuronal migration in the developing cortex (Bar et al., 1995; D’Arcangelo et al., 1995; Ogawa et al., 1995; Nakajima et al., 1997; Honda et al., 2011; Sekine et al., 2014); (2) a constitutive-active form of Fyn (CA-Fyn), a member of the Src family kinase (Arnaud et al., 2003); and (3) a dominant-negative form of Cdk5 (DN-Cdk5), a cyclin-dependent kinase known to be important during neuronal migration (Ohshima et al., 1996). Behavioral analyses revealed that the mice with heterotopias showed spatial working memory deficit and low competitive dominance behavior relative to the control mice. Furthermore, we directly manipulated the neural activity of the heterotopias by the DREADD (designer receptor exclusively activated by designer drug) system and found that activation of the ectopic neurons and their sister neurons in the overlying cortex located in the somatosensory area improved the spatial working memory deficit. Thus, our results indicate that focal heterotopias could affect the activities of distant brain areas and cause behavioral abnormalities.

\section{Materials and Methods}

Animals

Pregnant ICR mice were purchased from Japan SLC. All animal experiments were performed using protocols approved by the Keio University

Science Foundation, Keio Gijuku Fukuzawa Memorial Fund for the Advancement of Education and Research, Program for the Advancement of Keio Next Generation Research Projects, and Keio Gijuku Academic Development Funds. We thank the members of the K.N. laboratory for the valuable discussions and technical support; Drs. T. Curran (Reelin); J. Miyazaki (pCAGGS vector); T. Oshima (pCGC-Cdk5N144); T. Yamamoto (pME-B-Fyn Y531); and K. Deisseroth (ChR2 (C128S)) for providing the plasmids; and Dr. Shigeaki Kanatani and Dr. Takao Honda for construction of the pCAG-tdTomato (Kanatani et al., 2015) and pCAGGS1-Fyn Y531F vectors, respectively.

The authors declare no competing financial interests.

*K.I. and K.-i.K. contributed equally to this work.

Correspondence should be addressed to either of the following:Dr. Kazunori Nakajima, Department of Anatomy, Keio University School of Medicine, 35 Shinanomachi, Shinjuku-ku, Tokyo, 160-8582, Japan, E-mail: kazunori@keio.jp; or Dr. Masaki Kakeyama, Laboratory for Systems Neuroscience and Preventive Medicine, Waseda University Faculty of Human Sciences, Saitama, 359-1192, Japan, E-mail:kake@waseda.jp.

DOI:10.1523/JNEUROSCI.3648-14.2015

Copyright $\odot 2015$ the authors $\quad 0270-6474 / 15 / 3512433-14 \$ 15.00 / 0$
Institutional Animal Care and Use Committee in accordance with Institutional Guidelines on Animal Experimentation at Keio University, and the Japanese Government Law Concerning the Protection and Control of Animals and Japanese Government Notification of Feeding and Safekeeping of Animals. Embryonic day 19 (E19) was designated postnatal day 0 (P0). Dams, pups, and weaned animals were housed under a 12/12 $\mathrm{h}$ light/dark cycle in a temperature-controlled room. The animals were given free access to food and water, except during behavioral experiments. Animals were weaned at 3 weeks of age, at which time males were separated from females. All behavioral tests were performed with male mice.

\section{Construction of plasmids}

The full-length mouse Reelin expression construct pCrl was kindly provided by Dr. T. Curran (University of Pennsylvania). The coding sequence of Reelin from pCrl was inserted into pCAGGS1 containing a modified chicken $\beta$-actin promoter with the cytomegalovirusimmediate early enhancer (CAG) promoter (Niwa et al., 1991), kindly provided by Dr. J. Miyazaki (Osaka University), by using EcoRI and NotI sites, as previously reported (Kubo et al., 2010). To construct CAGtandem-Tomato fluorescent protein (tdTomato), the BamH I/NotI fragment of the tdTomato vector (Clontech) was introduced into the CAG-MCS2 vector (Kawauchi et al., 2005). pCGC-Cdk5N144 (pCGCDN-Cdk5) was obtained as a kind gift from Dr. Toshio Oshima (Waseda University). pCAGGS1-CA-Fyn was constructed from pME-B-Fyn Y531 (kindly provided by Dr. Tadashi Yamamoto, Okinawa Institute of Science and Technology Graduate University) and pCAGGS1. The EcoR I/SalI fragment (hM3Dq-mCherry) of the No. 41_pAAV-CMV-hM3DqmCherry (Inutsuka et al., 2014) was inserted into pCAGGS1 by using EcoR I and XhoI sites. Channelrhodopsin-2 (ChR2) (C128S)-EYFP (Berndt et al., 2009) was inserted into pCAGGS1 by using XbaI and EcoR I sites.

\section{In utero electroporation}

Pregnant mice at E14.5 were deeply anesthetized with pentobarbital sodium (Nembutal) administered by intraperitoneal injection, and their intrauterine embryos were surgically manipulated as described previously (Tabata and Nakajima, 2001). Plasmid solutions in volumes of 1-2 $\mu \mathrm{l}$ containing the vectors at concentrations of $1.0-7.5 \mathrm{mg} / \mathrm{ml}$ were injected into the lateral ventricles, and electronic pulses $(33 \mathrm{~V}, 50 \mathrm{~ms}, 4$ times) were applied using an electroporator (CUY-21 or NEPA21; NEPA GENE) with a forceps-type electrode (CUY650P5). To generate mice with heterotopias and control mice, pEGFP-CAGGS or pCAG-tdTomato was cotransfected at a concentration of $2.5 \mathrm{mg} / \mathrm{ml}$ with the Reelin expression vector ( $\mathrm{pCAGGS1-Reelin)} \mathrm{at} \mathrm{a} \mathrm{concentration} \mathrm{of} 7.5 \mathrm{mg} / \mathrm{ml}$ or the control expression vector ( $\mathrm{pCAGGS1)}$, respectively. To generate mice with heterotopias induced by CA-Fyn, pEGFP-CAGGS was cotransfected at a concentration of $2.0 \mathrm{mg} / \mathrm{ml}$ with the CA-Fyn expression vector ( $\mathrm{pCAGGS1-Fyn} \mathrm{Y531F)} \mathrm{at} \mathrm{a} \mathrm{concentration} \mathrm{of} 2.5 \mathrm{mg} / \mathrm{ml}$. To generate the mice with heterotopias induced by DN-Cdk5, the DN-Cdk5 expression vector ( $\mathrm{pCGC}-\mathrm{Cdk} 5 \mathrm{~N} 144$ ) was transfected at the concentration of $2.0 \mathrm{mg} / \mathrm{ml}$. To generate mice with heterotopias that expressed the hM3Dq-mCherry induced by CA-Fyn, pCAGGS1-hM3DqmCherry and pEGFP-CAGGS were cotransfected at a concentration of $2.5 \mathrm{mg} / \mathrm{ml}$ and $1.25 \mathrm{mg} / \mathrm{ml}$, respectively, with the pCAGGS1-Fyn $\mathrm{Y} 531 \mathrm{~F}$ at a concentration of $2.5 \mathrm{mg} / \mathrm{ml}$. To generate mice with heterotopias that expressed ChR2 (C128S)-EYFP induced by CA-Fyn, pCAGGS1-ChR2 (C128S)-EYFP and pEGFP-CAGGS were cotransfected at a concentration of $3.0 \mathrm{mg} / \mathrm{ml}$ and $3.0 \mathrm{mg} / \mathrm{ml}$, respectively, with the pCAGGS1-Fyn Y531F at a concentration of $3.0 \mathrm{mg} / \mathrm{ml}$.

\section{Bilateral in utero electroporation}

For introducing the plasmids into the somatosensory cortices bilaterally, the brains were transfected with pCAGGS1-Reelin, or pCAGGS1-Fyn $\mathrm{Y} 531 \mathrm{~F}$ and pEGFP-CAGGS vectors at concentrations of $2.5-7.5 \mathrm{mg} / \mathrm{ml}$ and $2.5 \mathrm{mg} / \mathrm{ml}$, respectively, followed immediately by transfection of pCAG-tdTomato at a concentration of $1 \mathrm{mg} / \mathrm{ml}$ into the contralateral hemisphere of E14.5 embryos. Because the second in utero electroporation was performed within 5 min of the first, the EGFP-labeled neurons and tdTomato-labeled neurons had the same birth date. To introduce the 
plasmids into the left mPFC and right somatosensory cortex sequentially, the pEGFP-CAGGS vector was injected into the left ventricle and transfected by in utero electroporation at E14.5. Immediately after transfection of pEGFP-CAGGS at the concentraion of $1 \mathrm{mg} / \mathrm{ml}$, pCAGGS1-Reelin, or pCAGGS1-Fyn Y531F and pCAG-tdTomato vectors at concentrations of $2.5-7.5 \mathrm{mg} / \mathrm{ml}$ and $2.5 \mathrm{mg} / \mathrm{ml}$, respectively, were introduced into the right somatosensory cortex by in utero electroporation. The second electroporation was performed within $\sim 5$ min of the first.

\section{Immunohistochemistry}

Coronal slices of the brains were prepared as described previously (Tabata and Nakajima, 2001). Sections were first washed with $0.05 \%$ Triton X-100 in PBS and then blocked in 10\% normal goat serum or $10 \%$ normal donkey serum and PBS for $30 \mathrm{~min}$. Sections were incubated with the primary antibody in 5\% normal goat serum or normal donkey serum, $0.05 \%$ Triton $\mathrm{X}-100$, and $\mathrm{PBS}$ at $4^{\circ} \mathrm{C}$ overnight. We used the following primary antibodies: rabbit anti-GABA (1:1000, Sigma), rabbit anti-CDP (Cux1) (1:200, Santa Cruz Biotechnology), rabbit anti-Tbr1 (1:1000, kindly provided by Dr. R. F. Hevner), rabbit anti-GFP (1:1000, MBL), mouse anti-NeuN (1:200, clone A60; Millipore), mouse anti-Satb2 (1: 200, SATBA4B10; Abcam), and rabbit anti-RFP (1:200, Rockland). To detect GABA, the sections were incubated at $85^{\circ} \mathrm{C}$ in $0.01 \mathrm{M}$ citrate buffer, $\mathrm{pH}$ 6.0, for $10 \mathrm{~min}$ before the treatment with the primary antibodies. To detect Cux1, NeuN, and Satb2, the sections were incubated at $70^{\circ} \mathrm{C}$ in HistoVT One (Nacalai Tesque) for $20 \mathrm{~min}$ before the incubation with the primary antibody. The sections were then rinsed several times with $0.05 \%$ Triton X-100 in PBS and incubated with fluorescence-conjugated secondary antibodies (goat Alexa-594 anti-rabbit or anti-mouse, donkey Alexa-555 anti-rabbit or anti-mouse, goat Alexa-488 anti-rabbit or antimouse, donkey Alexa-647 anti-rabbit or anti-mouse, 1:1000, Invitrogen) for $1 \mathrm{~h}$ at room temperature. In some sections, the nuclei were labeled with DAPI (1:5000, Invitrogen) or propidium iodide (1:1000, Invitrogen). Images were acquired through a confocal microscope (FV1000, Olympus) and fluorescence microscope (BX50, Olympus) equipped with a CCD camera (VB-7010, Keyence).

\section{Drug-induced seizure test}

Pentylenetetrazole (PTZ) (Sigma) was dissolved in $0.9 \% \mathrm{NaCl}$ and injected intraperitoneally every $10 \mathrm{~min}$ to P2 mice at a concentration of 25 $\mathrm{mg} / \mathrm{kg}$ and dose of $10 \mu \mathrm{l} / \mathrm{g}$ body weight. Injections of PTZ were continued until the drug elicited a generalized tonic-clonic seizure. Immediately after a generalized tonic-clonic seizure was observed, the mice were deeply anesthetized and fixed in $4 \%$ PFA. The seizure intensity was classified on Becker's 5 point scale (Becker et al., 2000), modified by Racine (Racine et al., 1972).

\section{Behavioral analyses}

$Y$-maze. Working memory was assessed by the spontaneous alteration behavior in the Y-maze test. The gray-painted maze has three arms, each arm being 40-cm-long, 15-cm-high, 3-cm-wide at the bottom and 12-cm-wide at the top. The test was conducted as described previously (Sarter et al., 1988; Maurice et al., 1994), with minor modifications. Each mouse (CA-Fyn, $n=13$; control, $n=14$; hM3Dqcontrol, $n=27$; hM3Dq-CA-Fyn, $n=15$; P6W male mice in each group were randomly selected from $4-7$ dams) was placed at the end of one arm and allowed to explore freely for $8 \mathrm{~min}$. Then, the series of arm entries was recorded both visually and by video recording. When the hindpaws of a mouse were placed on the arm, the mouse was considered to have entered the arm. Alternation behavior was defined as complete entry into the each arm, on overlapping triplet sets. The percentage alternation was calculated as the ratio of the actual (total alterations) to possible (total entries -2$) \times 100$. In the case of the hM3Dq-CA-Fyn and hM3Dq-control mice (see Fig. 6), the animals were given intraperitoneal administration of $6 \mathrm{mg} / \mathrm{kg}$ clozapine- $\mathrm{N}$ oxide $(\mathrm{CNO})$ or $0.9 \%$ saline $1 \mathrm{~h}$ before the task.

Three-chamber social interaction test. The arena of apparatus $(40 \times 60$ $\mathrm{cm}^{2}, 20$ lux, O'Hara) is divided into left, center, and right areas by transparent walls with a small opening. The left and right areas contain two round cages ( $8 \mathrm{~cm}$ in diameter) at the corner. The tests were performed as previously described (Faizi et al., 2012; Won et al., 2012), with slight modifications. In Session 1 for habituation, the mice with heterotopia or control mice (Reelin, $n=20$; control, $n=13$; P14-P19W male mice in each group were randomly selected from 5 dams; CA-Fyn, $n=8$; control, $n=8$; P16W male mice in each group were randomly selected from 4 dams) were placed in the center area and allowed to explore the whole arena freely for $10 \mathrm{~min}$. In Session 2, the mice were allowed $10 \mathrm{~min}$ explorations of the new environment of the arena where an inanimate object and a stranger mouse (stranger 1) occupied each cage. In Session 3 , the object was replaced with another stranger mouse (stranger 2), and the test mice were allowed to explore the arena freely for $10 \mathrm{~min}$. The behaviors of the mice were recorded using the ImageJ CSI software (O'Hara) The time spent in sniffing the cages, defined as touching the cage with the nose or forelimbs, was measured manually.

IntelliCage (TSE Systems): test apparatus. The mice were housed in the animal facility at a controlled temperature of $22^{\circ} \mathrm{C}-24^{\circ} \mathrm{C}$ and humidity of 40\%-60\%, under a 12/12 h light/dark cycle (lights on: 08:00-20:00 h). Male pups in each group (control, Reelin, CA-Fyn, DN-Cdk5) were randomly selected per 3-6 dams for the behavioral tests using IntelliCage to minimize litter effects. IntelliCage is a computer-based, fully automated testing apparatus that is used to analyze the spontaneous and cognitive behaviors of RFID-tagged mice in a home cage. In short, it is a large plastic cage $(55 \times 37.5 \times 20.5 \mathrm{~cm})$ equipped with four triangular operant learning chambers (corners, hereafter) $(15 \times 15 \times 21 \mathrm{~cm})$ that fit inside each corner of the cage. RFID readers, infrared sensors, and lickometers allow simultaneous monitoring of up to 16 RFID-tagged mice housed in the IntelliCage apparatus. The mice are allowed to enter the corner (corner visit, hereafter) through a short narrow tunnel that functions as an RFID antenna. Only one mouse can enter the corner at a time due to the limited size of the tunnel and the corner. In the inner space of the corner, the mice can access two nosepoke holes equipped with an infrared beambreak response detector. A nosepoke can trigger the opening of a motorized access gate to a water-bottle nozzle (gate, hereafter). In the IntelliCage, the time and duration of each behavioral event (corner visit, nosepoke, lick, etc), the mouse ID, and the corner ID are automatically recorded through the RFID readers, infrared sensors, and lickometers. A total of two IntelliCage apparatuses were used in this experiment. Acclimation: In this test, 7-month-old mice (Reelin, $n=9$; control, $n=7$ ) were housed and tested together in one IntelliCage apparatus throughout the experiment. All the mice were implanted with an RFID chip subcutaneously 1 week before the experiment, under anesthesia with diethyl either (Wako). The protocol of acclimation to the IntelliCage apparatus was based on that reported in a previous study, with some modifications. All the mice were introduced to the IntelliCage at 10:00 A.M. During the first $5 \mathrm{~d}$ of acclimation, the gates in all the corners through which mice could access the water-bottle nozzle were kept open, thereby allowing the mice to drink water ad libitum from all corners. Next, the shaping of the nosepoking behavior was performed for a total of $6 \mathrm{~d}$. In this phase, all the gates in front of the water bottle nozzle were closed initially so that the mice had to poke with their noses to open the gate and drink water. The gate could be opened by an action of a nosepoke and was closed $4 \mathrm{~s}$ later. During the first day of the shaping, the mice were able to obtain access to the water by nosepokes throughout the day. From the second day of shaping, the nosepokes allowed opening of the gates only for a $3 \mathrm{~h}$ period, from 22:00 to 01:00 h, during the dark phase. In other words, all the mice were deprived of water except during this $3 \mathrm{~h}$ period. A red light-emitting diode, which was attached to the outside of the cage, was kept dimly lit throughout the $3 \mathrm{~h}$ period to signal the water availability period. Likewise, during this period, the red light-emitting diodes in the corners were lit when the mice made a visit. Competition task: After the acclimation, the competition task was initiated. Similar to the case in the last phase of acclimation, the mice were deprived of water throughout the test period, except for the $3 \mathrm{~h}$ period of 22:00 to 01:00 h every day. During the $3 \mathrm{~h}$ period, the mice were permitted to drink water for $4 \mathrm{~s}$ in each corner visit after the first nosepoke. Staying in or reentering the same corner did not yield the reward of additional water. The behaviors of the mice with Reelin-induced heterotopias and the control mice were compared in a total of 52 sessions. In Sessions 1-28, all the mice competed to enter the four corners for drinking water after the period of water deprivation (first highly competitive condition). In Sessions 29- 
35 , the mice were divided into groups and tested in different cages (less competitive condition). Subsequently, after Session 35 (Sessions 35-50), they were again housed together and tested in a same cage (second highly competitive condition). The duration of the corner visit per minute and the latency to reach the peak of the corner visit duration after the session had started were used as indices to assess the level of dominance of the mice under the competitive condition for the water reward. For the case of the mice with heterotopia induced by CA-Fyn (CA-Fyn, $n=8$; control, $n=8$ ) and DN-Cdk5 (DN-Cdk5, $n=8$; control, $n=8$ ), the competition task was performed with 3 -month-old mice for $13 \mathrm{~d}$ after acclimation.

\section{ISH}

ISH has been described previously (Bepari et al., 2012). In brief, to detect c-fos mRNA, hybridization was performed with digoxigenin (DIG)labeled c-fos cRNA probes (Pizoli et al., 2002). DIG-labeled c-fos cRNA was allowed to react with an alkaline phosphatase-conjugated anti-DIG antibody (1:5000 dilution, Roche), with NBT/BCIP (Roche) used as the chromogen. The sections were counterstained with Nuclear Fast Red (Sigma).

\section{Laser microdissection and mRNA quantification}

The prelimbic (PrL) and anterior cingulate cortex (ACC) regions were dissected by laser microdissection (LMD7000, Leica Microsystems) from the brain tissues obtained within an hour after the last behavioral test and collected into the caps of $0.2 \mathrm{ml}$ microtubes (BIO-BIK BT-02LC, InaOptika). Regions from the right and left hemisphere were collected into separate microtubes, and analyzed separately, for each mouse. The total volume of the collected laser-microdissected tissues ranged from 600,000 to 1 million $\mu \mathrm{m}^{2} \times 20 \mu \mathrm{m}$; the tissues were spun down by centrifugation at $15,000 \times g$ for $1 \mathrm{~min}$ and then suspended in the CellAmp Processing Buffer (CellAmp Direct RNA Prep Kit, Takara) containing proteinase K (0.3 U, Takara) in a volume of $2.0 \mu \mathrm{l}$ per $100,000 \mu \mathrm{m}^{2}$ of the collected tissues. Following $30 \mathrm{~min}$ of incubation at $50^{\circ} \mathrm{C}$, the samples were sonicated for $1 \mathrm{~min}$ and incubated at $75^{\circ} \mathrm{C}$ for $5 \mathrm{~min}$ to inactivate proteinase K. CellAmp Processing Buffer containing DNase I (CellAmp Direct RNA Prep Kit; Takara) in a 9:1 ratio was added to the RNA-containing solution $\left(0.5 \mu \mathrm{l}\right.$ per $100,000 \mu \mathrm{m}^{2}$ of the collected tissues) and incubated at $37^{\circ} \mathrm{C}$ for $5 \mathrm{~min}$. Following addition of a mixture of Easy Dilution (Takara) and RNase-free water in a 1.25:1 ratio $\left(4.5 \mu \mathrm{l}\right.$ per $100,000 \mu \mathrm{m}^{2}$ of collected tissues), the DNase I was inactivated by incubation at $75^{\circ} \mathrm{C}$ for $5 \mathrm{~min}$. The solution containing RNAs was reverse-transcribed using PrimeScript (Takara) with both oligo-dT20 and random N6 primers. Gene expression analysis was performed by SYBR Green I-based real-time PCR using a Light Cycler instrument (Roche Molecular Biochemicals) and the Thunderbird qPCR mix (Toyobo). Primers were designed as shown below (18SrRNA, forward, GGACCAGAGCGAAAGCATTTG; reverse, TTGCCAGTCGGCATCGTTTAT; Arc, forward, CAGAGCCAGGAGA ATGACAC; reverse, GCAGCTTCAGGAGAAGAGAG).

In vivo electrophysiological recording and optogenetics: surgical preparation. Mice at 6 weeks of age were anesthetized with urethane $(1.6 \mathrm{~g} / \mathrm{kg})$ and fixed to a stereotaxic apparatus (SR-6M, Narishige Scientific Instrument). Their body temperature was maintained at $37 \pm 0.5^{\circ} \mathrm{C}$ using a heating pad during the surgical and recording procedures. A craniotomy ( $\sim 1 \mathrm{~mm}$ in diameter) was performed to make two holes: one $2.0 \mathrm{~mm}$ anterior to the bregma and $0.5 \mathrm{~mm}$ lateral to the midline on the right, and the other $1.5 \mathrm{~mm}$ posterior to the bregma and $2.5 \mathrm{~mm}$ lateral to the midline on the left. An optical fiber ( $\varnothing 0.5 \mathrm{~mm}$, Eska, Mitsubishi Rayon) was inserted into the latter hole and fixed at $1.5 \mathrm{~mm}$. A silicon probe (linear 16-electrode array, $100 \mu \mathrm{m}$ interval, $177 \mu \mathrm{m}^{2}$ recording site area, $15 \mu \mathrm{m}$ thickness, NeuroNexus Technologies) coated with DiI (D-282, Invitrogen; $80 \mathrm{mg} / \mathrm{ml}$ in a 50:50 methanol/acetone mixture) was inserted into the first hole to a depth of $1.8 \mathrm{~mm}$. Two small screws were inserted into the occipital bone in contact with dura for grounding and reference. Extracellular recording, illumination: Recording sessions were started $>1$ $\mathrm{h}$ after the insertion of the probes. Local field potentials (LFPs) were recorded at $24.42 \mathrm{kHz}$ with a bandpass filter $(0.1 \mathrm{~Hz}$ to $5 \mathrm{kHz})$ after being amplified (10,000×) (TDT RZ-2, Tucker-Davis Technologies). The LFPs were filtered between 300 and $3000 \mathrm{~Hz}$ to detect multiunit activities. To activate the step-function opsin, ChR2(C128S), a blue and yellow light pair $(475 \mathrm{~nm}, 3.8 \mathrm{~mW}$ at the tip of an fiber, $0.5 \mathrm{~s}$ duration and $575 \mathrm{~nm}, 4.5$ $\mathrm{mW}, 1 \mathrm{~s}$; Lumencor SPECTRA light engine, Lumencor) was delivered with a $30 \mathrm{~s}$ interval.

\section{Data analyses}

To analyze the density of the GABAergic interneurons in Figure $1 V-X$, images of the somatosensory cortex were obtained and the numbers of the cells in the heterotopias and normal upper cortical layers were counted using the ImageJ $1.43 \mathrm{u}$ software (Wayne Rasband, National Institutes of Health); the percentage of these cells relative to the total cell counts in the corresponding areas (the heterotopias or normal upper cortex) were calculated. We used Student's $t$ test to compare two independent groups. In Figure 1Y, the average cumulative doses of PTZ that were needed to induce generalized tonic-clonic seizures were calculated and tested by Student's $t$ test. In Figure $3 A$, data were analyzed by a paired $t$ test to determine the preference for either cage within each group, and by Student's $t$ test to analyze the difference between two groups. In Figure $3 B-F$, the means \pm SEM of the latencies to reach the peaks of the corner visit durations in the heterotopia group were compared with those in the control group by multiple comparisons with Bonferroni's correction. The results of one-way ANOVA followed by Bonferroni's test for multiple group comparisons are shown in Figure $4 B$. In Figure $4 C$, the expression levels of Arc-mRNAs in the PrL and ACC are presented as copy numbers relative to the expression level of $18 \mathrm{~S}$ rRNA, calculated using standard curves. The copy number of Arc in each group was compared with control group by Student's $t$ test. In Figure 5, data from the acquired units were stored in a disk and analyzed using software custom-written in MATLAB (The MathWorks). All data were expressed as mean \pm SD. A two-factor mixed ANOVA followed by a simple main effect test with a Benjamini and Hochberg multiple testing correction was used for the statistical analysis of electrophysiological data. Values were considered statistically significant at $p<0.05$. In Figure 6, one-way ANOVA followed by Tukey's honestly significant difference (HSD) test was used for multiple group comparisons.

\section{Results}

\section{Generation of a mouse model of heterotopias that persisted for a long time, similar to human heterotopias}

Ectopic expression of Reelin by in utero electroporation induced neuronal aggregation in the developing mouse neocortex (Kubo et al., 2010). To examine whether the mouse with Reelin-induced neuronal aggregation is a valid model for investigation of human heterotopias, we characterized the aggregates in the postnatal stages. We performed in utero electroporation at embryonic day (E) 14.5 to introduce the expression vectors for Reelin and EGFP, and analyzed the brains in the postnatal stage (Fig. 1A). The EGFP-labeled cells formed heterotopias mainly in the white matter, whereas some EGFP-positive cells that did not participate in the heterotopias (hereafter referred to as "sister neurons in the overlying cortex") were located in the upper cortical layers (Fig. $\left.1 B, B^{\prime}, C\right)$. In most of the animals, the heterotopias persisted for at least 6 months after the electroporation (data not shown). Transfection of the expression vectors for CA-Fyn or DN-Cdk5 also caused aggregation of ectopic neurons within the subcortical regions, similar to the Reelin-induced heterotopias (Fig. $1 D, E$ ). To examine whether these three types of heterotopias shared similar features, we performed immunohistochemical analyses for the layer markers. The majority of the cells within the heterotopias were NeuN-positive, a marker of mature neurons (Fig. $1 G-I^{\prime}$ ), Cux1-positive, a marker of layer II/III and IV neurons (Fig. $1 \mathrm{~K}-$ $M^{\prime}$ ), and Satb2-positive, a callosal neuron marker (Fig. 1O- $Q^{\prime}$ ). By contrast, cells positive for Tbr1, a marker of layer VI and subplate neurons, were scarcely observed (Fig. $1 S-U^{\prime}$ ). Thus, the three types of heterotopias induced by different molecules (Reelin, CA-Fyn, and DN-Cdk5) showed common cellular identities. 


\section{A} EP to somatosensory cortex Reelin or CA-Fyn or DN-Cdk5

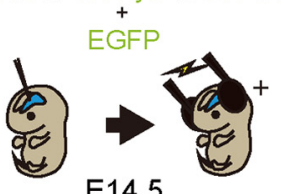

E14.5

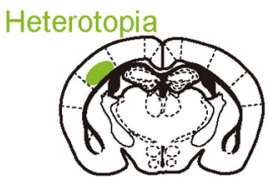

Heterotopia

(Reelin)

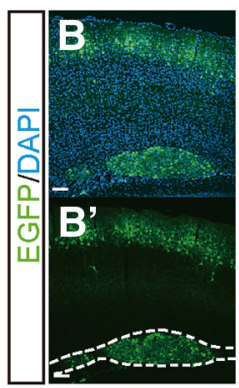

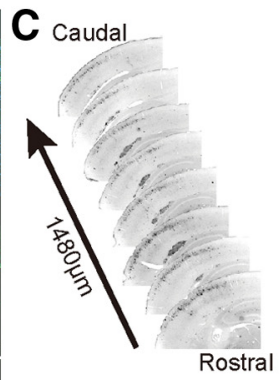

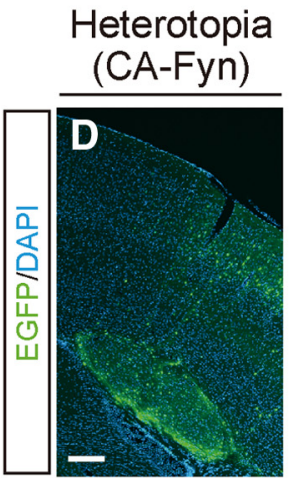

Heterotopia (DN-Cdk5)

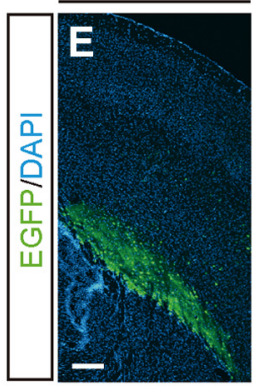

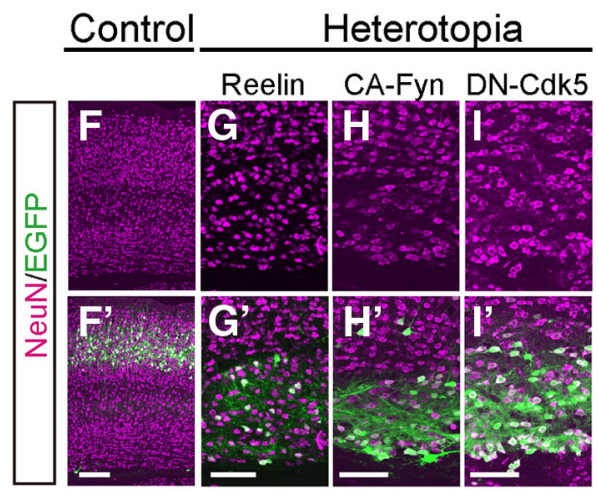
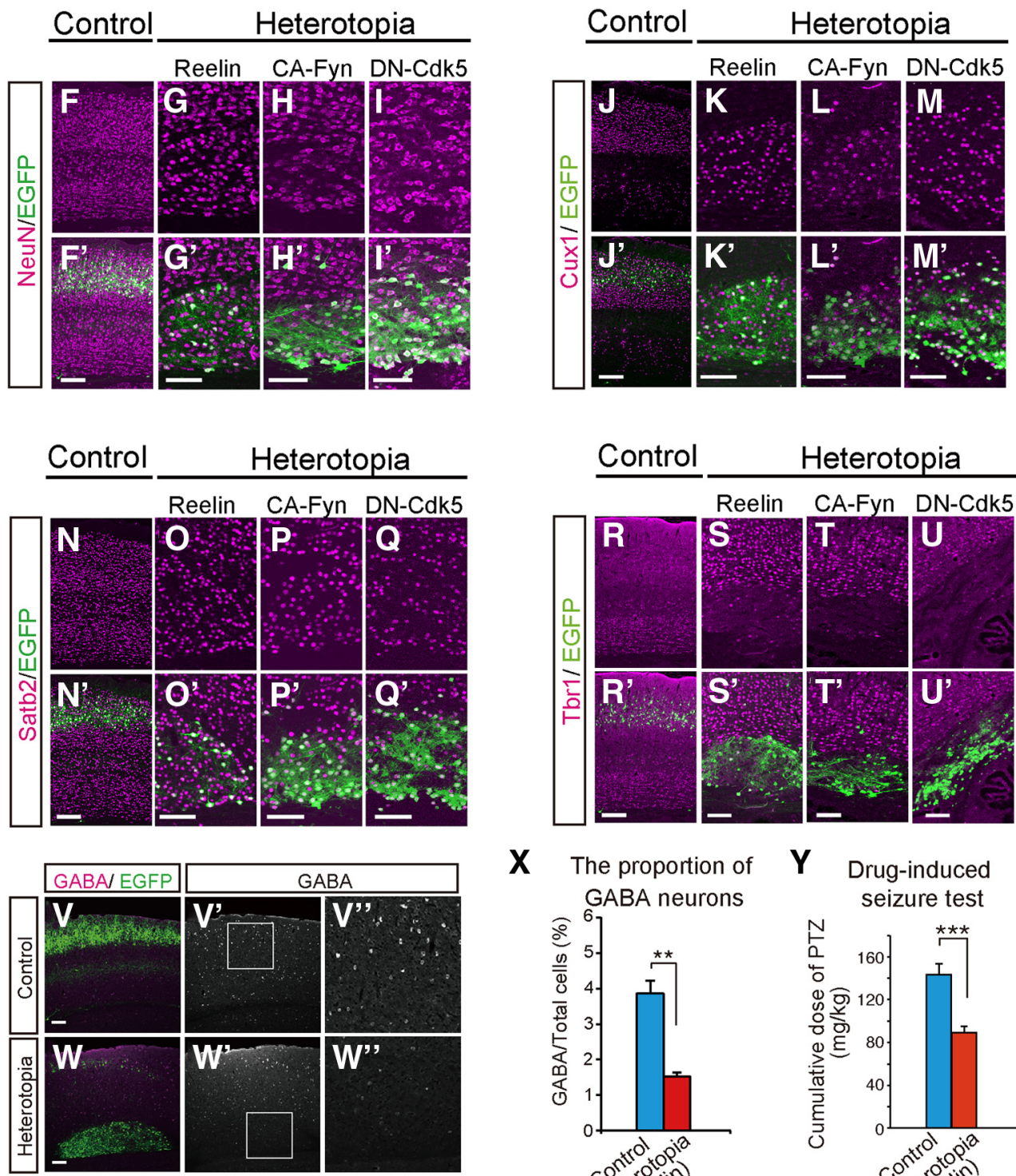

\section{$\mathrm{X}$}

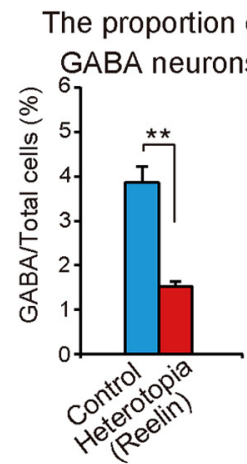

$Y$

Drug-induced

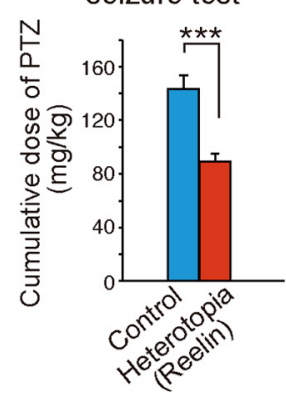

Figure 1. Ectopic expression of Reelin resulted in the formation of subcortical heterotopias in the postnatal mouse cortex. $A$, Schematic representation of the in utero electroporation at E14.5. The coronal brain schema is shown. Green circle represents the Reelin-induced heterotopia located in the somatosensory cortex. $\boldsymbol{B}, \boldsymbol{B}^{\prime}$, Heterotopias in the white matter in the P14.5 mouse neocortex following transfection of both Reelin and EGFP at E14.5. Nuclei counterstained with DAPI (cyan). The area between the two dashed lines indicates the white matter. Scale bars, $100 \mu \mathrm{m}$. $C$, Eight serial coronal sections of the P14.5 mouse brains are shown. The heterotopias are distributed along the rostrocaudal axis over a length of $\sim 1480 \mu \mathrm{m}$. Each section was $20 \mu \mathrm{m}$ thick. The grayscale images of EGFP are inverted. D, A P30 brain with a heterotopia induced by CA-Fyn. E14.5 brains electroporated with pCAG-CA-Fyn and EGFP expression vectors and fixed at P30. Nuclei counterstained with DAPI. Scale bar, $200 \mu \mathrm{m}$. E, Heterotopic neurons located within the white matter in the P16 brain transfected with DN-Cdk5. E14.5 brains electroporated with the CGC-DN-Cdk5 and EGFP expression vectors and fixed at P16. Nuclei counterstained with DAPI. Scale bar, $200 \mu \mathrm{m}$. F-U', E14.5 brains transfected with Reelin, CA-Fyn, DN-Cdk5, or pCAGGS1 (control) and EGFP expression vectors, and fixed at P14 (Reelin, CA-Fyn, and control) or P16 (DN-Cdk5). F-I', Brains immunostained with anti-NeuN antibody (magenta), a marker of mature neurons. Heterotopias (Figure legend continues.) 
Next, we checked the number of GABAergic interneurons in the heterotopias (induced by Reelin) using an anti-GABA antibody. The proportion of GABA-positive cells in the cells within the heterotopias was significantly lower than that in the upper cortical layers (layer II-IV) in the control mice ( $p=0.00034$, Student's $t$ test) (Fig. $1 V-X$ ). The significant decrease in the proportion of GABA-positive cells in the heterotopias indicates that the ratio of excitatory/inhibitory neurons might be altered in heterotopias compared with that in the normal overlying cortical layers.

Human patients with heterotopias frequently manifest epilepsy. Hence, we next tested whether mice with heterotopias (induced by Reelin) also showed increased seizure susceptibility using PTZ, a convulsant agent (Manent et al., 2009). In the mice with heterotopias, the average cumulative dose of PTZ required to induce a generalized tonic-clonic seizure was significantly lower $(89.5 \pm 5.5 \mathrm{mg} / \mathrm{kg}, n=19)$ compared with that in the control mice (143.4 $\pm 9.9 \mathrm{mg} / \mathrm{kg}, n=19)$ (Fig. $1 Y ; p=0.000031$, Student's $t$ test), consistent with the results of previous studies showing that heterotopias tended to elicit seizures in both humans and animal models (Sisodiya, 2004; Manent et al., 2009). We did not find any apparent spontaneous seizure in the mice with heterotopias, whereas we cannot exclude the possibility that the mice had small focal seizures.

\section{The cortical regions containing the heterotopias were connected to other brain regions}

Because the neurons within the heterotopias expressed markers for callosal neurons (Fig. $1 O-Q^{\prime}$ ), we predicted that the heterotopias might be reciprocally connected to the layer II/III neurons in the contralateral cortex. To examine this possibility, we performed bilateral in utero electroporation. To visualize the axonal projections from the contralateral hemisphere to the cortex with the heterotopias, we transfected Reelin or CA-Fyn and EGFP first, followed immediately thereafter by transfection of tdTomato to the contralateral hemisphere (Fig. 2A). The results of the examination revealed that the tdTomato-labeled cells were normally located in the layer II/III of the contralateral hemisphere and extended their axons through the corpus callosum toward the opposite hemisphere. In the control brains, the arborization of the tdTomato-labeled axons in the opposite hemisphere was

\footnotetext{
$\leftarrow$

(Figure legend continued.) induced by Reelin, CA-Fyn, and DN-Cdk5 are shown in $\left(\boldsymbol{G}, \boldsymbol{G}^{\prime}\right),(\boldsymbol{H}$, $\left.\boldsymbol{H}^{\prime}\right)$, and $\left(\boldsymbol{I}, \boldsymbol{I}^{\prime}\right)$, respectively. Scale bars: $\boldsymbol{F}^{\prime}, 200 \mu \mathrm{m} ; \boldsymbol{G}^{\prime}, \boldsymbol{H}^{\prime}, \boldsymbol{I}^{\prime}, 100 \mu \mathrm{m}$. $\boldsymbol{J}-\boldsymbol{M}^{\prime}$, Sections were immunostained with anti-Cux1 (magenta), a marker of layer II-IV neurons. Heterotopias induced by Reelin, CA-Fyn, and DN-Cdk5 are shown in $\left(\boldsymbol{K}, \boldsymbol{K}^{\prime}\right),\left(\boldsymbol{L}, \boldsymbol{L}^{\prime}\right)$, and $\left(\boldsymbol{M}, \boldsymbol{M}^{\prime}\right)$, respectively. Scale bars: $J^{\prime}, 200 \mu \mathrm{m} ; \boldsymbol{K}^{\prime}, \boldsymbol{L}^{\prime}, \boldsymbol{M}^{\prime}, 100 \mu \mathrm{m}$. $\boldsymbol{N}-\boldsymbol{Q}^{\prime}$, Sections were immunostained with antiTbr1 (magenta), a marker of deep layer neurons. Heterotopias induced by Reelin, CA-Fyn, and DN-Cdk5 are shown in $\left(\mathbf{0}, \mathbf{O}^{\prime}\right),\left(\boldsymbol{P}, \boldsymbol{P}^{\prime}\right)$, and $\left(\mathbf{Q}^{\prime} \mathbf{Q}^{\prime}\right)$, respectively. Scale bars: $\boldsymbol{N}^{\prime}, 200 \mu \mathrm{m} ; \mathbf{O}^{\prime}, \boldsymbol{P}^{\prime}$, $\boldsymbol{Q}^{\prime}, 100 \mu \mathrm{m} . \boldsymbol{R}-\boldsymbol{U}^{\prime}$, Brains with heterotopias were immunostained with an antibody against Satb2 (magenta), a marker of callosal neurons. Heterotopia induced by Reelin, CA-Fyn, and DN-Cdk5 are shown in $\left(\boldsymbol{S}, \boldsymbol{S}^{\prime}\right),\left(\boldsymbol{T}, \boldsymbol{T}^{\prime}\right)$, and $\left(\boldsymbol{U}, \boldsymbol{U}^{\prime}\right)$, respectively. Scale bars: $\boldsymbol{R}^{\prime}, 200 \mu \mathrm{m} ; \boldsymbol{S}^{\prime}, \boldsymbol{T}^{\prime}$, $U^{\prime}, 100 \mu \mathrm{m}$. $\boldsymbol{V}-\boldsymbol{X}$, Quantitative analysis of GABAergic interneurons in the brains with heterotopias and control brains was performed. $\boldsymbol{V}-\boldsymbol{V}^{\prime \prime}$, P28 control brains transfected with EGFP at E14.5. $\boldsymbol{W}-\boldsymbol{W}^{\prime \prime}$, P28 brains with heterotopias that were transfected with Reelin and EGFP at E14.5. The GABAergic interneurons (magenta or gray) immunostained with anti-GABA antibody. $\boldsymbol{V}^{\prime \prime}, \boldsymbol{W}^{\prime \prime}$, Higher-magnification images of the areas in the white squares in $\boldsymbol{V}^{\prime}$ and $\boldsymbol{W}^{\prime}$, respectively. Scale bars: $\boldsymbol{V}, \boldsymbol{W}, 100 \mu \mathrm{m}$. $\boldsymbol{X}$, Data are mean \pm SEM of the proportion of GABApositive neurons relative to the total cell count in the heterotopias and normal upper layers of the cortex are shown ( $n=5$ each). ${ }^{* *} p=0.00034$ (Student's $t$ test). $\boldsymbol{Y}$, Statistical analyses of the cumulative dose of PTZ that induced generalized seizures in the mice with heterotopias and the control mice at P28. ${ }^{* *} p=0.000031$ (Student's $t$ test). $n=19$ each. Data are mean \pm SEM.
}

clearly visualized (Fig. $2 B, E$ ). Interestingly, when the heterotopias were formed, the contralateral neuron-derived tdTomatopositive fibers heavily invaded the heterotopias (Fig. $\left.2 C-D^{\prime \prime \prime}\right)$, and few tdTomato-labeled fibers reached the cortex overlying the heterotopias (Fig. 2F, white arrows). These findings indicate that focal heterotopias could affect the contralateral cortical functions through disruption of the normal corticocortical circuits.

During our investigation, we observed the axonal projections from the heterotopias to the amygdala. To visualize the amygdala as well as the projections from the heterotopias and their overlying sister neurons, we performed in utero electroporation sequentially and bilaterally (Fig. $2 G$ ). First, the left mPFC was transfected with EGFP by in utero electroporation at E14.5, as previously described (Niwa et al., 2010), to visualize the amygdala that is targeted by the left mPFC. Immediately thereafter, Reelin and tdTomato expression vectors were introduced into the right somatosensory cortex and the mice were killed at P14.5. The neurons in the medial wall of the PFC, which includes the PrL and ACC, were labeled with EGFP (Fig. 2H), and the basolateral amygdala (BLA) was clearly visualized by the mPFC-derived EGFP-positive axon terminals (Fig. $2 J-K^{\prime}$ ). In the somatosensory cortex, tdTomato-positive heterotopias were located in the white matter. A proportion of the sister neurons in the overlying cortex were also transfected (Fig. 2I). Importantly, we observed that many tdTomato-positive fibers reached the ipsilateral BLA, whereas the contralateral BLA also received a few tdTomato-positive axons (Fig. $2 J-K^{\prime}$ ), indicating that the axons derived from the heterotopias and their overlying sister neurons projected to the BLA. These results suggest that neurons in the cortical region containing the heterotopias send axons to the amygdala.

Collectively, these histological analyses revealed that the cortical regions containing the heterotopias and their sister neurons were connected with other brains regions (e.g., the contralateral cortex and amygdala).

\section{Mice with heterotopias showed behavioral alterations}

Because autistic behaviors have been reported in human patients with focal heterotopias, we examined whether focal heterotopias also affected mouse behavior. To examine the sociability of the mice with heterotopias induced by Reelin or CA-Fyn, we performed the three-chamber sociability tests. First of all, the results revealed no preference of the mice for a vacant cage during habituation in either the heterotopia group or the control group (Reelin, $p=0.26$; control, $p=0.82$, paired $t$ test; Fig. $3 A a$, left graph; CA-Fyn, $p=0.77$; control, $p=0.27$, paired $t$ test; Fig. $3 A d$, left graph). In Session 2, performed for assessment of the sociability, all groups preferred the mouse over the object $(p<0.001$, paired $t$ test), and the time spent sniffing at the mouse was similar between the groups (Reelin vs control, $p=0.061$; CA-Fyn vs control, $p=0.97$, Student's $t$ test; Fig. $3 A b, A e$, middle graph). In Session 3, performed to test social recognition, both groups showed preference for the stranger mouse $(p<0.05$, paired $t$ test), and there were no significant differences between the two groups (Reelin vs control, $p=0.90$; CA-Fyn vs control, $p=0.75$; Fig. $3 A c, A f$, right graph). Together, we demonstrated that the sociability and social recognition of mice with heterotopias were comparable with those of the control mice in the three-chamber test.

To further evaluate the social behavior, we used the IntelliCage apparatus (TSE Systems), which is a fully automated behavioral testing system that sensitively detects the behavioral alterations of mice in a group-housed environment (Endo et al., 2012; Benner et al., 2014). During the first day of acclimation, the number of corner visits during the first $4 \mathrm{~h}$ was used as the index 
A
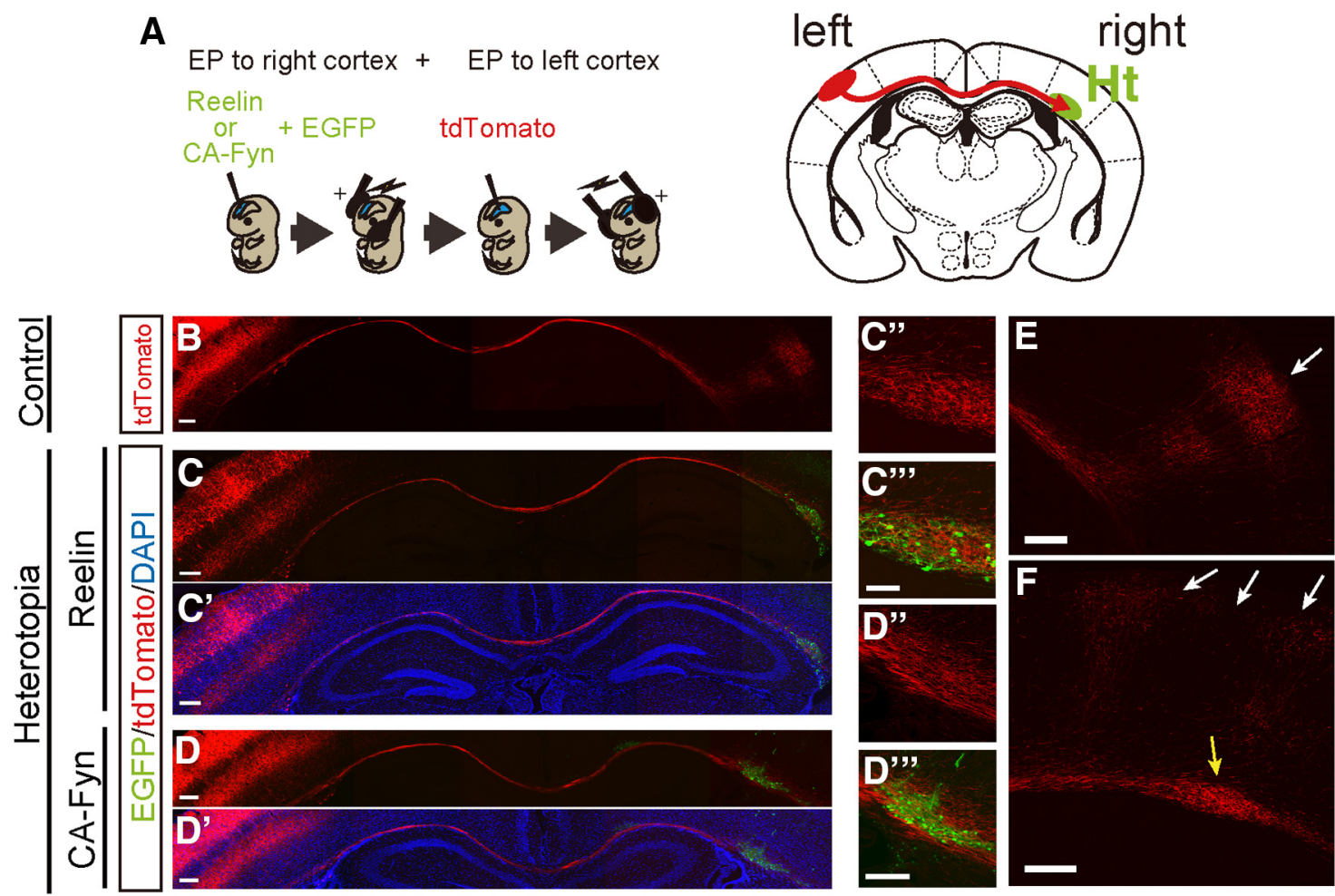

G
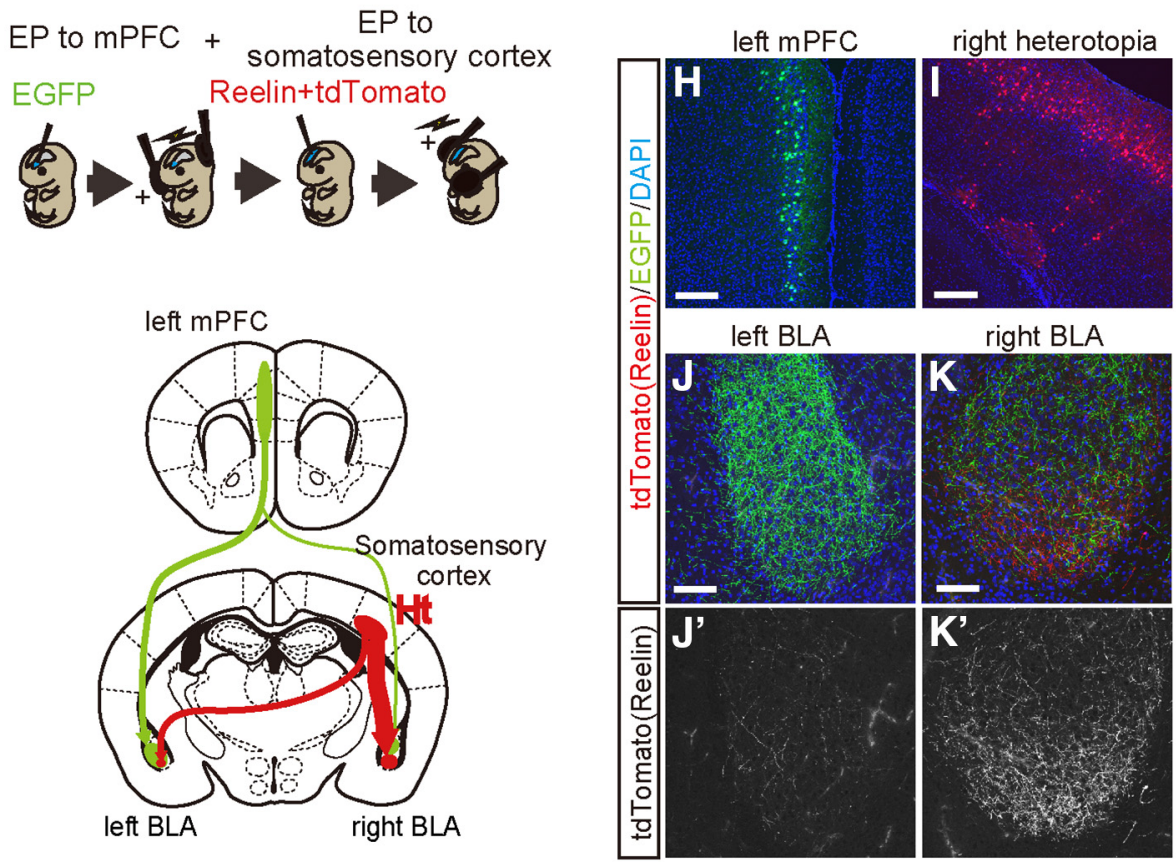

Figure 2. Connections were formed between the cortical region containing the heterotopias and other brain regions. $A$, Schematic representation showing the procedure of in utero electroporation to the somatosensory cortex of both sides. The brain scheme illustrates the callosal projections (a red arrow) from the left hemisphere extending into the heterotopia (Ht) in the right cortex (green) through the corpus callosum. $\boldsymbol{B}$, Control brains electroporated with tdTomato only in the left somatosensory cortex. C- $\boldsymbol{D}^{\prime \prime \prime}$, EGFP-positive cells (green) distributed within the heterotopia (C-C'", Reelin; $\boldsymbol{D}-\mathbf{D}^{\prime \prime \prime}, \mathbf{C A}-$-Fyn) and in the overlying cortex. tdTomato-positive fibers (red) from the left cortex extending into the heterotopia located in the right cortex. Nuclei counterstained with DAPI (blue). $\boldsymbol{C}^{\prime \prime}, \boldsymbol{C}^{\prime \prime \prime}$, Higher-magnification images of $\boldsymbol{F}$. $\boldsymbol{D}^{\prime \prime}, \boldsymbol{D}^{\prime \prime \prime}$, Higher-magnification images of $\boldsymbol{D}$. $\boldsymbol{E}$, High-magnification image of the portion in the right part in $\boldsymbol{B}$. White arrow indicates the projections from contralateral hemisphere. $\boldsymbol{F}$, Contralateral axons were found projecting into the regions with Reelin-induced heterotopia (yellow arrow). White arrows indicate the projections from the contralateral hemisphere. Scale bars: $\boldsymbol{B}-\boldsymbol{C}^{\prime}, \boldsymbol{D}, \boldsymbol{D}^{\prime}, \boldsymbol{D}^{\prime \prime \prime}, \boldsymbol{E}, \boldsymbol{F}, 200 \mu \mathrm{m} ; \boldsymbol{C}^{\prime \prime \prime}, 100 \mu \mathrm{m}$. $\mathbf{G}$, Illustrations represent the procedures of the sequential and bilateral in utero electroporation. A schematic representation showing the projections from the heterotopia (red) and the $\mathrm{mPFC}(\mathrm{green})$ to the BLA. $\boldsymbol{H}-\boldsymbol{K}^{\prime}$, P14.5 brains show the left mPFC and right heterotopia labeled with GFP and tdTomato, respectively. The green cells are mPFC neurons (H). tdTomato-positive (red) heterotopia and the overlying cortex were observed in the left somatosensory cortex $(\boldsymbol{I})$. $\boldsymbol{J}-\boldsymbol{K}^{\prime}$, Both EGFP- and tdTomato-labeled axons terminated in the BLA bilaterally. Nuclei counterstained with DAPI (blue). Scale bars: $\boldsymbol{H}, \boldsymbol{I}, 200 \mu \mathrm{m} ; \boldsymbol{J}, \boldsymbol{K}, 100 \mu \mathrm{m}$. 
A

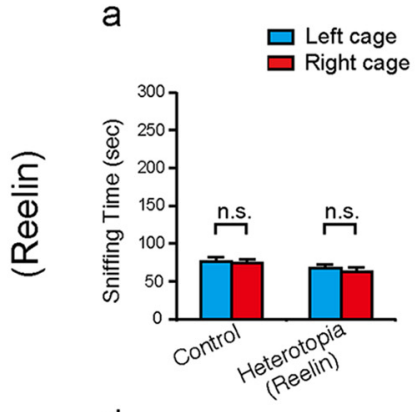

d

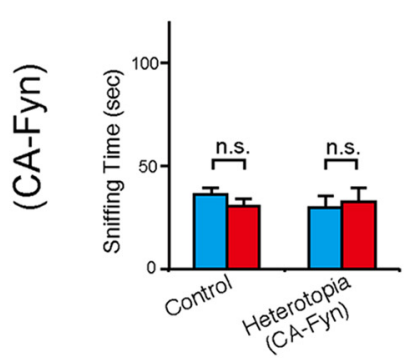

Three-Chamber Sociability Test

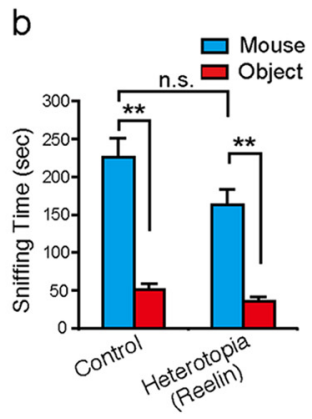

e

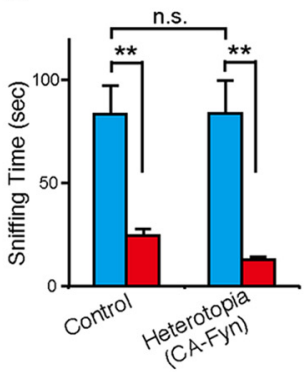

C

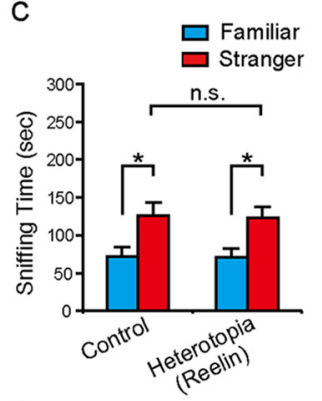

f

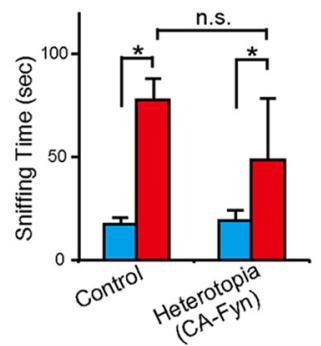

B Exploratory behavior
C
Competition task

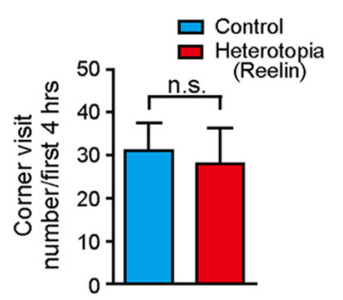

Basal activity
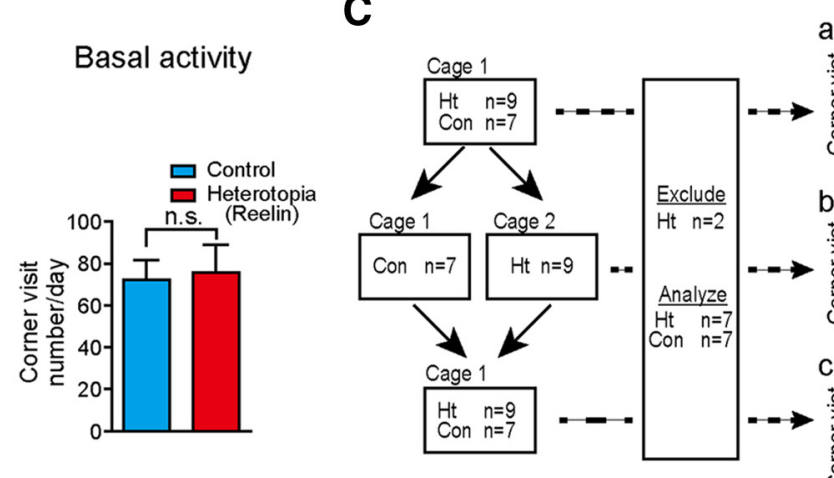

. $20 .-$ High (1st)
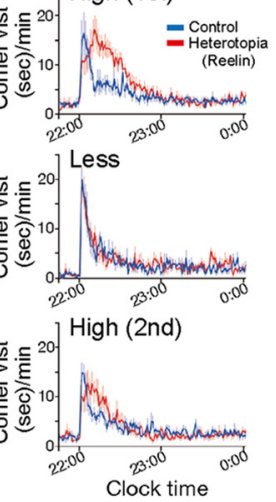

D Latency to peak (Reelin)

E Latency to peak (CA-Fyn)
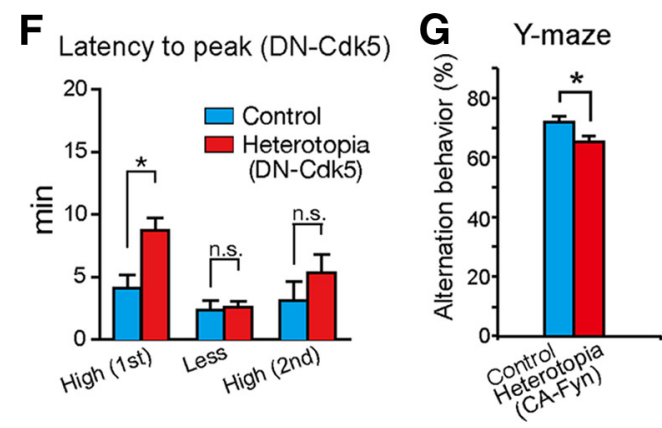

Figure 3. Micewith heterotopias exhibitabnormal behaviors. $\boldsymbol{A}$, Three-chamber sociability tests of the mice with heterotopias induced by Reelin (Aa-Ac) and the mice with heterotopias induced by $C A-F y n(A d-A f)$. Left graphs $(\boldsymbol{A} \boldsymbol{a}, \boldsymbol{A d})$ represent the total sniffing times of the control mice and mice with heterotopias in the left and right vacant cages during habituation. Middle graphs ( $\boldsymbol{A} \boldsymbol{b}, \boldsymbol{A} \boldsymbol{e})$ represent the total times spent in sniffing the miceortheobjects. Right graphs $(\boldsymbol{A c}, \boldsymbol{A f})$ represent the total times spentsniffing the familiar miceand thestrangermice. Dataaremean \pm SEM. ${ }^{*} p<0.05$ (paired ttest). ${ }^{* *} p<0.001$ (pairedttest).n.s., Notsignificant. $\boldsymbol{B}$, Left graph represents the average number of comer visits of each group during the first $4 \mathrm{~h}$ (acclimation day 1). Right graph represents the average number of comer visits of each group per day (acclimation day 2-5). C, Left part represents the experimental flow chart of the behavioral test using the Intellicage. Two mice with heterotopias were excluded because of severe hydrocephalus; finally, 7 mice with heterotopias and 7 control mice were analyzed. Graphs represent the cornervisitduration during the 2 hthroughoutthesessionsfor each group in the competitiontask. Ca, Cc, Thedurations of the comervisits under thefirstand second highly competitive condition, respectively. $\boldsymbol{C} \boldsymbol{b}$, The durations under the less competitive condition. $\boldsymbol{D}-\boldsymbol{F}$, The latency to reach the peaks of the corner visit durations under each condition (first highly competitive, less competitive, and second highly competitive) are shown as mean \pm SEM. $\boldsymbol{D}$, Reelin-induced heterotopia group versus the control group (Reelin, $n=7$; control, $n=7$ ). ${ }^{*} p=0.037$ (multiple comparison test with Bonferroni correction). $\boldsymbol{E}$, Data for the CA-Fyn-induced heterotopia group versus the control group (CA-Fyn, $n=8$; control, $n=8$ ). ${ }^{*} p=0.013$ (multiple comparison test with Bonferroni correction). ${ }^{* *} p=0.00010$ (multiple comparison test with Bonferroni correction).F, DatafortheDN-Cdk5-induced heterotopiagroupversusthecontrol group (DN-Cdk5, $n=8$; control, $n=8$ ). ${ }^{*} p=0.0070$ (multiple comparisontestwith Bonferronicorrection). High (first), firsthighlycompetitive condition; Less, less competitive condition; High (second), second highly competitive condition. G, Graph showing the alternation behavior in the mice with heterotopias induced by CA-Fyn and the control mice (heterotopias, $65.9 \pm 1.5 \%, n=15$; control, $71.9 \pm 1.9 \%, n=14) .{ }^{*} p=0.023$ (Student's t test). Data are mean \pm SEM. 
of novel environment-induced exploratory behavior. From days 2-5 (acclimation period), the number of corner visits was considered to reflect the basal activity.

In our first statistical analysis, we did not find any significant differences in the behavioral phenotype between the Reelininduced heterotopia group and the control group (data not shown) (heterotopia, $n=9$; control, $n=7$ ). However, in our later histological analyses of the brains, we found that two mice in the Reelin-induced heterotopia group showed severe hydrocephalus, which is a well-described artifact caused occasionally by the in utero electroporation technique itself (Tabata and Nakajima, 2008). Because the hydrocephalus could cause nonspecific brain dysfunction, we performed a reanalysis of the data after excluding these two mice with hydrocephalus from the Reelin-induced heterotopia group (heterotopia, $n=7$; control, $n=7$ ) (Fig. $3 B-D$ ).

As with the results, we found no statistically significant differences in the exploratory behavior or basal activity between the groups (Fig. 3B), suggesting the absence of any differences in the motivation and motor functions between the two groups. Under the highly competitive condition, during which the mice had to compete to occupy the corners with rewards, the latency to reach the peak of corner visit duration in the heterotopia group was significantly higher compared with that in the control group ( $p=$ 0.037, multiple comparison test with Bonferroni correction) (Fig. $3 C a, D$ ). This indicated that the mice with heterotopias showed low dominance behavior under the highly competitive condition. Under the subsequent less competitive condition, during which the heterotopia group and control group were separated from each other and tested in two IntelliCage apparatuses, the difference in the latency to reach the peak of corner visit duration was diminished (Fig. $3 C b, D$ ). This result showed that the delayed latency to reach the peak of corner visit duration under the highly competitive condition in the heterotopia group was not due to a low motivation for the water reward. Finally, under the subsequent highly competitive condition again, during which all the mice were kept together and tested in a single IntelliCage apparatus again, the latency to reach the peak of corner visit duration in the heterotopia group was again delayed compared with that in the control group, although the difference did not reach statistical significance (Fig. $3 C c, D$ ). Moreover, the mice with heterotopias induced by CA-Fyn and DN-Cdk5, which did not show hydrocephalus, also showed low dominance behaviors under the highly competitive condition (Fig. $3 E, p=0.00010, p=$ 0.013 ; Fig. $3 F, p=0.0070$, multiple comparison test with Bonferroni correction), suggesting that the low competitive behavior was not simply produced by Reelin, but by the presence of focal heterotopias in the somatosensory cortex. Thus, together with the consistent results across the three types of heterotopias, these observations indicate that the mice with focal heterotopias displayed a low competitive dominance behavior.

Because the low competitive dominance behavior was most obvious in the mice with heterotopias induced by CA-Fyn compared with the other two models (Fig. 3E), we used the CA-Fyn-induced heterotopia for the subsequent experiments. Next, to further examine whether the mice with heterotopias exhibited cognitive dysfunction (e.g., working memory deficit), the spontaneous alternation behavior was assessed by the Y-maze test. The percentage alternation of the mice with heterotopias (CA-Fyn) was significantly lower than that of the control mice (heterotopia, $65.9 \pm 1.5 \%, n=15$; control, $71.9 \pm 1.9 \%, n=14, p=0.023$, Student's $t$ test) (Fig. $3 G$ ).

Dominance hierarchy-related behavior and a spatial working memory have been shown to be closely associated with the mPFC activity in rodents (Seamans et al., 1998; Wang et al., 2011; Endo
A

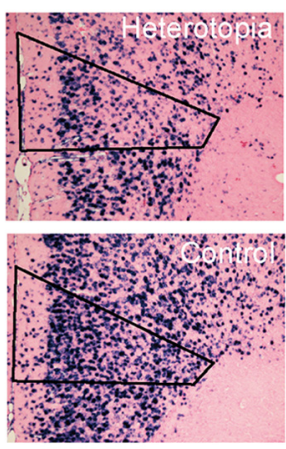

C

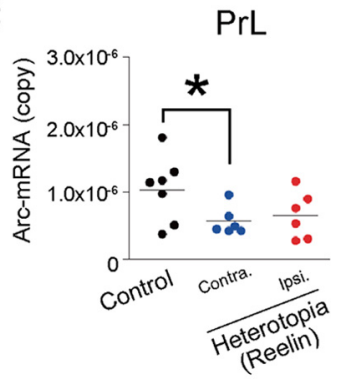

B c-fos mRNA expression in PrL
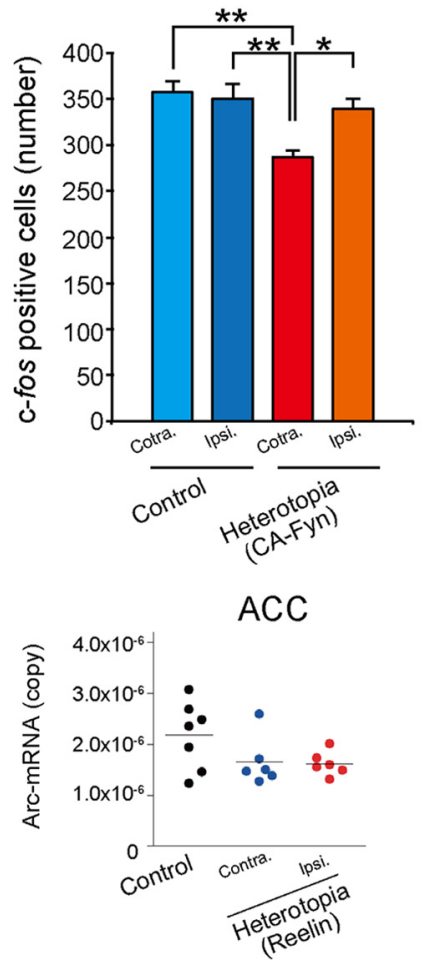

Figure 4. Immediate-early gene expression was decreased in the brain ( $\mathrm{PrL}$ ) with heterotopias. $\boldsymbol{A}$, Representative mPFC images of the brains with heterotopias induced by CA-Fyn (Heterotopia) and control brains (Control). ROls indicate PrL area. $\boldsymbol{B}$, Quantitative analysis of the number of c-fos-positive cells in the PrL (CA-Fyn, $n=13$; control, $n=14$ ). Data are mean \pm SEM. ${ }^{*} p<0.05,{ }^{* *} p<0.001$ (one-way ANOVA followed by Bonferroni test). C, Quantification of Arc mRNA in the ACC and PrL regions in the mice with heterotopias and the control mice by qPCR. Blue and red dots indicate the data from regions contralateral (contra.) and ipsilateral (ipsi.) to the heterotopias, respectively (Heterotopia, $n=6$; Control, $n=7$ ). ${ }^{*} p=0.049$ (Student's $t$ test).

et al., 2012). Therefore, we hypothesized that the neuronal activity in the MPFC might be decreased in the mice with heterotopias. To examine this, we performed ISH analysis for c-fos expression, an immediate-early gene, in the mPFC. The number of c-fospositive cells in the contralateral PrL regions was significantly decreased in the mice with heterotopias induced by CA-Fyn compared with the control mice (Fig. $4 A, B$; one-way ANOVA, $F=$ $6.25, p=0.0011$, heterotopia, $n=13$; control, $n=14, p=0.0016$, control contra. vs heterotopia contra.; $p=0.0052$, control ipsi. vs heterotopia contra.; $p=0.036$, heterotopia ipsi. vs heterotopia contra., Bonferroni test).

To investigate whether the decrease of the neuronal activity in the MPFC was also observed in other heterotopia models, we next measured the mRNA expression levels of Arc, a gene induced by synaptic activity, in the brains with Reelin-induced heterotopias. The PrL and ACC regions in the MPFC were obtained by laser microdissection, and the amount of Arc mRNA in each region was compared between the heterotopia group and controls by quantitative PCR (qPCR). The copy number of Arc mRNA in the contralateral $\operatorname{PrL}$ was significantly decreased in the mice with heterotopias compared with that in the controls. Arc mRNA expression in the ipsilateral PrL and ACC was also decreased in the mice with heterotopias, although the difference did not reach statistical significance (Fig. $4 C ; p=0.049$, Student's $t$ test). These results are consistent with the above-mentioned results from the 
A
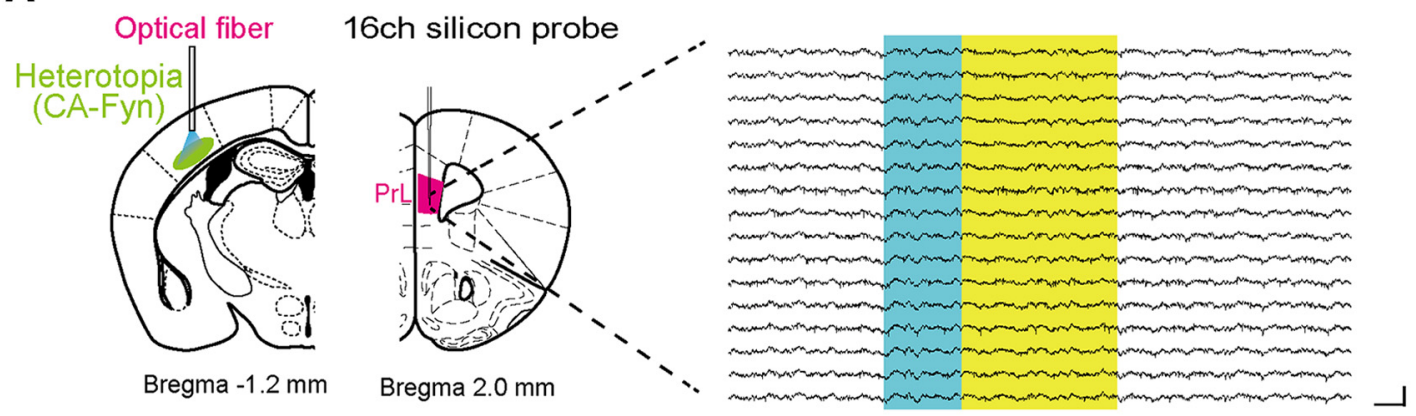

B

C
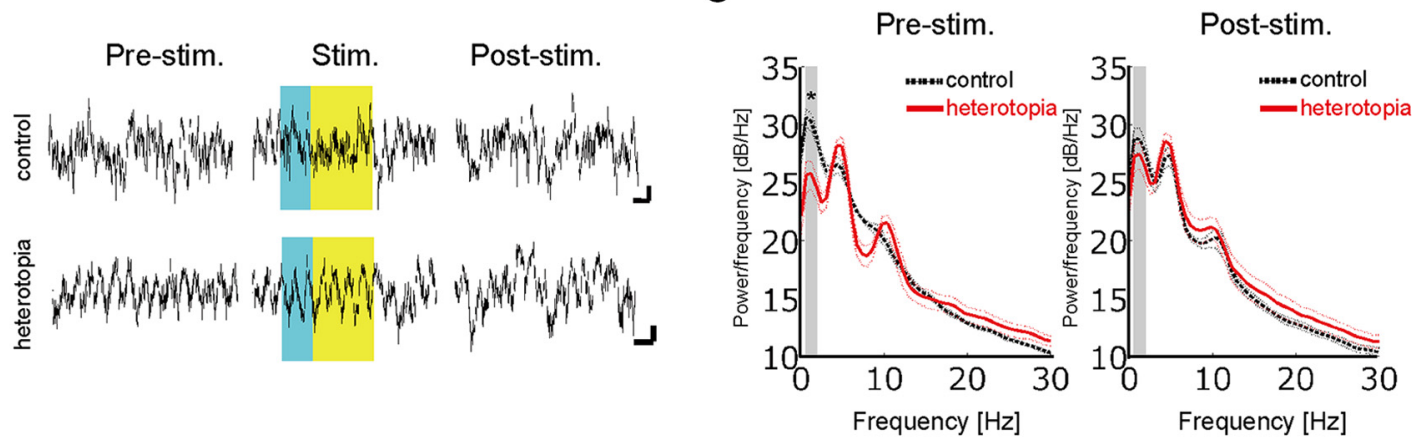

Figure 5. Heterotopias in the somatosensory cortex altered the LFP activities of the mPFC. $A$, Left, Experimental setup for in vivo electrophysiological recording from the PrL (magenta) and optogenetic stimulation of CA-Fyn-induced heterotopia (green). An optical fiber and a 16-ch silicon probe were inserted into the brain just above the PrL and the heterotopia, respectively. Right, Representative LFP traces from the PrL of a mouse with heterotopia. Blue and yellow areas represent the effect of light illumination by the respective colors, on the heterotopias in the somatosensory cortex. Calibration: $1 \mathrm{mV}, 0.2$ s. B, Expanded view of representative LFP traces from the PrL of mice with or without heterotopias. Pre-stim., prestimulation; stim., stimulation; post-stim., poststimulation. Calibration: $0.1 \mathrm{mV}, 0.3$ s. C, Power spectrum densities of the LFPs from the PrL of mice with and without heterotopias recorded before (left panel) and after (right panel) optical stimulation of the somatosensory cortex. Gray areas represent the $\delta$-band $(0.5-3.5 \mathrm{~Hz})$. The LFP power at the $\delta$-band before stimulation (left panel) was lower in the mice with heterotopias than in the control mice. ${ }^{*} p<0.05$ (two-factor mixed ANOVA).

brains with CA-Fyn-induced heterotopias, suggesting that the $\mathrm{mPFC}$ activity is decreased in mice with heterotopias.

Presence of heterotopias in the somatosensory cortex reduced the $\delta$-band power of the local field potentials in the mPFC

To examine more directly whether the presence of focal heterotopias in the somatosensory cortex indeed altered the neural activities of the MPFC, we measured the LFPs from the deep layer of the PrL region under spontaneous or optogenetically stimulated conditions (Fig. 5A). For manipulating the activities of the ectopic neurons and their sister neurons in the overlying cortex, we used the step-function opsin ChR2(C128S), whose channels could be opened or closed by blue and yellow light illumination, respectively. The pCAG-ChR2(C128S)-EYFP was coelectroporated with pCAG-EGFP and pCAG-CA-Fyn (heterotopia) or a mock vector (pCAGGS1, control) into E14.5 brains; subsequently, the P6W mice were examined by in vivo electrophysiological analysis.

First, we observed the spontaneous electrical activities in the mice with and without heterotopias (Fig. 5B). In the frequency analysis, the LFP powers in the $\delta$-band $(0.5-3.5 \mathrm{~Hz})$ and the $\theta$-band $(6.0-9.0 \mathrm{~Hz})$ tended to be lower in the mice with heterotopia than in the control mice (Fig. $5 C$, left). Especially, the LFP power in the $\delta$-band $(0.5-3.5 \mathrm{~Hz})$ was significantly lower in the mice with heterotopias than in the control mice (Fig. $5 C$, Prestim., LFP power: $166.5 \pm 4.9$ vs $145.4 \pm 5.2, n=5$ each, $F_{(1,8)}=$ $6.88, p<0.05$, a simple main effect of prestimulation vs poststimulation of heterotopia mouse, following two-factor mixed ANOVA with a between-subjects factor [control vs heterotopias] and a within-subjects factor [pre-stim. vs post-stim], which revealed no significant main effects and marginal significance in interaction $\left.\left[F_{(1,8)}=4.50, p<0.10\right]\right)$, indicating that the presence of heterotopias in the somatosensory cortex altered the neural activities of the PrL. However, when we stimulated the activities of the ectopic neurons and their overlying sister neurons expressing ChR2 (C128S), the profiles of the LFP power in the mice with heterotopias became similar to those in the control mice (Fig. 5 C, right), whereas we did not find statistically significant changes in the LFP power of the mPFC after stimulation compared with that before stimulation in any group of mice $\left(F_{(1,8)}=1.95\right.$ for control, $F_{(1,8)}=2.57$ for heterotopia, not significant, respectively, twofactor mixed ANOVA, $n=5$ each). One possible explanation for this is that the number of stimulated neurons was not sufficiently large to significantly change the activity of the mPFC because the optical light was assumed to stimulate only small populations of neurons within the heterotopias. Nevertheless, the above results indicate that the existence of heterotopias in the somatosensory cortex indeed altered the neural activities of the MPFC.

\section{Activation of the ectopic neurons and their overlying sister neurons in the somatosensory cortex improved the spatial working memory deficit in the mice with heterotopias}

Finally, we examined whether the mouse behavior could be influenced by the changes of the neuronal activity in the heterotopias. We manipulated the neural activity of the ectopic neurons and their overlying sister neurons during the behavioral tests using the DREADD system. We used hM3Dq, a $\mathrm{G}_{\mathrm{q}}$-coupled receptor that responds specifically to $\mathrm{CNO}$ and induces depolariza- 
A EP to somatosensory cortex

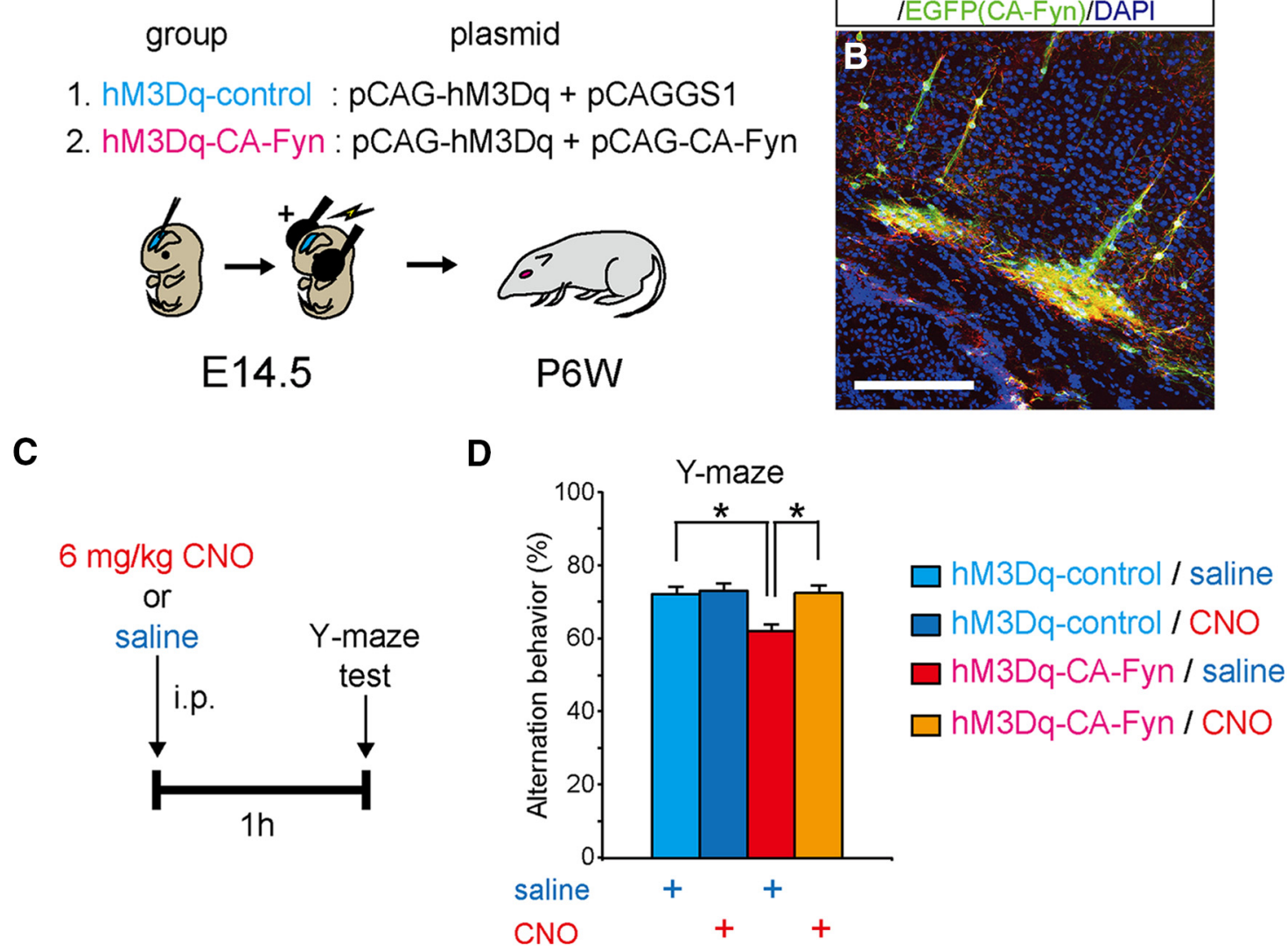

Figure 6. Manipulating the neural activities of the ectopic neurons using the DREADD system improved the spatial working memory deficit in the mice with heterotopias. $A$, A schematic representation of the in utero electroporation at E14.5. An hM3Dq-expressing vector (pCAG-mCherry-hM3Dq) was coelectroporated with pCAG-EGFP and pCAG-CA-Fyn or pCAGGS1. B, An image of the P6W brain with heterotopias. An hM3Dq-mCherry expression vector was cotransfected with the CA-Fyn and EGFP expression vectors into E14.5 brains and fixed at P6 weeks. The brain was immunostained with anti-RFP antibody (red). Scale bar, $200 \mu \mathrm{m}$. C, Scheme represents the time course of the injection of CN0 or saline and the behavioral test. D, Graph represents the spontaneous alternation behavior in the Y-maze test of the hM3Dq-control/saline $(n=14)$, hM3Dq-control/CNO $(n=13)$, hM3Dq-CA-Fyn/saline $(n=6)$, and hM3Dq-CA-Fyn/CNO $(n=9)$ mice. Data are mean \pm SEM. ${ }^{*} p<0.05$ (Tukey's HSD test).

tion of the pyramidal neurons (Alexander et al., 2009). An hM3Dq-expressing vector (pCAG-mCherry-hM3Dq) was coelectroporated with pCAG-EGFP and pCAG-CA-Fyn (hM3DqCA-Fyn) or pCAGGS1 (a mock vector, hM3Dq-control) into E14.5 brains (Fig. 6A). The expression of hM3Dq was confirmed by the expression of mCherry protein at postnatal 6 weeks (Fig. $6 B)$. We performed the Y-maze tests in the mice expressing $\mathrm{hM} 3 \mathrm{Dq}$ to assess the spatial working memory in the presence or absence of CNO. The mice were intraperitoneally administered with $6 \mathrm{mg} / \mathrm{kg}$ CNO or $0.9 \%$ saline $1 \mathrm{~h}$ before the task (Fig. $6 \mathrm{C}$ ). The mice with heterotopias administered with saline (hM3DqCA-Fyn/saline) exhibited significant deficit in the spatial working memory (Fig. 6D; hM3Dq-control/saline, $71.9 \pm 2.1 \%, n=14$; hM3Dq-CA-Fyn/saline, $61.9 \pm 2.9 \%, n=6, p=0.031$, Tukey's HSD test). Interestingly, however, the alternation behavior of hM3Dq-CA-Fyn mice in the presence of CNO (Fig. 6D; hM3DqCA-Fyn/CNO, $72.3 \pm 2.1 \%, n=9$ ) was comparable with that of control mice (Fig. 6D; hM3Dq-control/saline, $71.9 \pm 2.1 \%, n=$ 14 ; hM3Dq-control/CNO, $72.9 \pm 2.0 \%, n=13, p>0.05$, respectively, Tukey's HSD test). These data suggest that activation of the ectopic neurons and their overlying sister neurons in the somatosensory cortex could improve the spatial working memory deficit.

\section{Discussion}

For the generation of heterotopias using in utero electroporation, we first introduced Reelin as reported previously (Kubo et al., 2010). Reelin is known to be associated with schizophrenia and bipolar disorder (Shifman et al., 2008; Goes et al., 2010; Liu et al., 2010), suggesting that Reelin is involved in higher brain functions. Moreover, we and another group recently found that supplementation of Reelin prevented the behavioral deficits related to schizophrenia and bipolar disorder (Teixeira et al., 2011; Ishii et al., 2015). Thus, there was a possibility that the Reelin protein itself might have influenced the mouse behaviors if the focal heterotopia models were created only by Reelin overexpression. Therefore, we also used in utero electroporation of CA-Fyn and DN-Cdk5 to examine whether the mice with heterotopias induced by these molecules showed behavioral abnormalities. The IntelliCage experiments revealed that all the mice with heterotopias induced by Reelin, CA-Fyn, or DN-Cdk5 exhibited low competitive dominance behavior, lending support to the notion that the presence of heterotopias, and not Reelin, was responsible for the behavioral deficits. We cannot, however, completely exclude the possibility that Reelin-induced synaptic modifications and promotion of dendritogenesis during the developmental and postnatal stages might have further modified the neuronal activ- 
ities in our Reelin-induced heterotopia model (Weeber et al., 2002; Niu et al., 2004; Pujadas et al., 2010).

Within the heterotopias, we observed that the majority of neurons expressed the markers of superficial layer neurons, but not those of the deep layer neurons (Fig. $1 F-U^{\prime}$ ). This is reasonable because the electroporation was performed at E14.5, when the superficial layer neurons just begin to be born (Takahashi et al., 1999). The deep layer neurons are generated before this stage, and it is likely that they have already completed their migration when the heterotopias are being formed.

In terms of the low proportion of GABAergic neurons in the heterotopias (Fig. $1 V-X$ ), it is not clear whether it was caused by insufficient integration of GABAergic neurons into the heterotopia or by cell death, etc., after they were integrated. If the former were true, it would be interesting to investigate how these GABAergic neurons migrated toward the heterotopias. Cortical GABAergic neurons are known to be born mainly in the ganglionic eminences and to migrate tangentially into the cortex (Nakajima, 2007). When they enter the cortex, they move through the subventricular zone/intermediate zone or through the marginal zone into the developing cortex (Tanaka and Nakajima, 2012). The latter population temporarily shows random walk movement within the marginal zone and then finally invades the cortical plate to settle in a neuronal birth date-dependent manner (Miller, 1985; Yozu et al., 2004; Tanaka et al., 2009). If the GABAergic neurons in the heterotopias in our model were supplied by both the subventricular zone/intermediate zone and the marginal zone, the migrating cells derived from the latter might have been "trapped" in the cortical plate before reaching the white matter, resulting in the low proportion of the GABAergic neurons in the heterotopias.

The mice with heterotopias exhibited low competitive dominance behavior and spatial working memory deficit (Fig. $3 B-G$ ), which have been shown to be associated with the activity of the mPFC in rodents. Indeed, we observed decreased expression of immediate-early genes in the PrL of the mice with heterotopias (Fig. 4), which reflects alteration of the synaptic activities, and a decreased power of the $\delta$-band $(0.5-3.5 \mathrm{~Hz})$ of the LFPs in the PrL of these mice (Fig. $5 C$, left), suggestive of mPFC dysfunction. These findings indicate that the presence of heterotopias in the somatosensory cortex affected the neural activities in the mPFC. Furthermore, the deficit in spatial working memory was no longer detected when the transfected neurons, including those in the heterotopias, were activated in the DREADD system experiments (Fig. 6D). Why were the behavioral phenotypes rescued in the DREADD system experiments? Despite the abnormal neural activities of the mPFC in the mice with heterotopias, our histological analysis revealed no direct axonal connections between the mPFC neurons and the heterotopias (data not shown). Thus, one possible explanation is that the heterotopias and their sister neurons form a functional neuronal circuit that is connected to the mPFC. As a result, the activity of the mPFC may be remotely controlled by the neurons within the heterotopias and their sister neurons through this circuit. Indeed, we found that the ectopic neurons and their sister neurons had neuronal connections with the BLA and the contralateral cortex (Fig. $2 A-K^{\prime}$ ). In addition, there is a possibility that the heterotopias and their sister neurons are connected to regions other than the BLA and the contralateral cortex, although we did not investigate all the connection profiles of the heterotopias and their sister neurons. Therefore, in our stimulation experiments, the activity of the MPFC might have been indirectly restored by modulation of the activities of other regions connected to the heterotopias, their sister neurons, and the $\mathrm{mPFC}$, resulting in the mitigation of behavioral alterations.

Furthermore, in the optogenetics experiment, the differences in the electrical activities of the mPFC between the mice with heterotopias and the control mice largely disappeared after the light stimulation of the somatosensory cortex (Fig. $5 C$, right). However, no significant differences in the LFP power were recorded between the prestimulation and poststimulation periods in any of the heterotopia or control groups (two-factor mixed ANOVA; Fig. 5C). On the other hand, the LFP power in the heterotopia group was significantly lower than that in the control group in the prestimulation period ( $p<0.05$, two-factor mixed ANOVA; Fig. 5C, left). Namely, within each group, optogenetic activation of the transfected neurons had no significant effect on the neuronal activities in the mPFC. These results appear to be less clear compared with the data obtained from the DREADD system experiments. Because the heterotopias were distributed over a long distance along the rostrocaudal axis (Fig. 1C), the proportion of neurons stimulated by optical light was assumed to be relatively small among the heterotopias; therefore, the activation might not have been sufficiently strong to produce any significant change in the activity of the mPFC. By contrast, in the DREADD system, almost all neurons that expressed the transfected receptors could be stimulated because $\mathrm{CNO}$, an activator of the recombinant receptors, was administered systemically and was considered to therefore have the ability to reach all the transfected receptors.

In human cases of periventricular nodular heterotopia caused by mutation in the X-linked gene Filamin A (FLNA), there is a possibility that the neurons located outside the heterotopias (not only the overlying sister neurons but also other neurons) also show impairments in their dendrites and spines (Nagano et al., 2004). Thus, the impaired neurons located outside the heterotopias may also be involved in the development of various clinical symptoms in human cases. However, we could not address this possibility using our mouse models because of the technical limitations of examining the neurons outside the cortical region containing the heterotopias, which are assumed to be impaired in human cases of periventricular nodular heterotopia, in our mouse models. Additionally, we could neither quantify the extent of axonal projections from the heterotopias into the BLA or the contralateral cortex, nor evaluate the projections from the overlying sister neurons, comparing with those from the superficial layer neurons in the normal cortex. Some studies have shown that the overlying cortex also showed structural and functional abnormalities in mouse brains with heterotopias (Ackman et al., 2009). Thus, the cortex overlying the heterotopias might also exert an influence on the neural activities of the mPFC in coordination with the heterotopias in the present study. In other words, the cortical region containing the focal heterotopias as a whole ("normally positioned overlying sister neurons" plus "ectopically positioned neurons") might affect distant brain regions, leading to behavioral abnormalities. Because the expression constructs, including ChR2 and hM3Dq, were transfected into both ectopic neurons and the overlying sister neurons, both of these populations would have been stimulated by light or $\mathrm{CNO}$ in these experiments. It is thus not clear whether the mPFC dysfunction was mitigated only (or mainly) by the activation of neurons in the heterotopias or whether activation of their overlying sister neurons might also have contributed to this mitigation. Indeed, we cannot exclude the possibility that the behavioral deficits might have been caused/worsened by the decrease in the number of superficial layer neurons in the mice with heterotopias. In any case, the 
present study indicates that the formation of focal heterotopias in the somatosensory cortex directly or indirectly affected the activities of the mPFC, causing behavioral abnormalities.

\section{References}

Ackman JB, Aniksztejn L, Crépel V, Becq H, Pellegrino C, Cardoso C, Ben-Ari Y, Represa A (2009) Abnormal network activity in a targeted genetic model of human double cortex. J Neurosci 29:313-327. CrossRef Medline

Aghakhani Y, Kinay D, Gotman J, Soualmi L, Andermann F, Olivier A, Dubeau F (2005) The role of periventricular nodular heterotopia in epileptogenesis. Brain 128:641-651. CrossRef Medline

Alexander GM, Rogan SC, Abbas AI, Armbruster BN, Pei Y, Allen JA, Nonneman RJ, Hartmann J, Moy SS, Nicolelis MA, McNamara JO, Roth BL (2009) Remote control of neuronal activity in transgenic mice expressing evolved $\mathrm{G}$ protein-coupled receptors. Neuron 63:27-39. CrossRef Medline

Amodio DM, Frith CD (2006) Meeting of minds: the medial frontal cortex and social cognition. Nat Rev Neurosci 7:268-277. CrossRef Medline

Arnaud L, Ballif BA, Förster E, Cooper JA (2003) Fyn tyrosine kinase is a critical regulator of disabled-1 during brain development. Curr Biol 13: 9-17. CrossRef Medline

Bar I, Lambert De Rouvroit C, Royaux I, Krizman DB, Dernoncourt C, Ruelle D, Beckers MC, Goffinet AM (1995) A YAC contig containing the reeler locus with preliminary characterization of candidate gene fragments. Genomics 26:543-549. CrossRef Medline

Becker A, Grecksch G, Thiemann W, Höllt V (2000) Pentylenetetrazolkindling modulates stimulated dopamine release in the nucleus accumbens of rats. Pharmacol Biochem Behav 66:425-428. CrossRef Medline

Benner S, Endo T, Endo N, Kakeyama M, Tohyama C (2014) Early deprivation induces competitive subordinance in C57BL/6 male mice. Physiol Behav 137:42-52. CrossRef Medline

Bepari AK, Watanabe K, Yamaguchi M, Tamamaki N, Takebayashi H (2012) Visualization of odor-induced neuronal activity by immediate early gene expression. BMC Neurosci 13:140. CrossRef Medline

Berndt A, Yizhar O, Gunaydin LA, Hegemann P, Deisseroth K (2009) Bistable neural state switches. Nat Neurosci 12:229-234. CrossRef Medline

Chang BS, Ly J, Appignani B, Bodell A, Apse KA, Ravenscroft RS, Sheen VL, Doherty MJ, Hackney DB, O'Connor M, Galaburda AM, Walsh CA (2005) Reading impairment in the neuronal migration disorder of periventricular nodular heterotopia. Neurology 64:799-803. CrossRef Medline

Clark GD (2004) The classification of cortical dysplasias through molecular genetics. Brain Dev 26:351-362. CrossRef Medline

D’Arcangelo G, Miao GG, Chen SC, Soares HD, Morgan JI, Curran T (1995) A protein related to extracellular matrix proteins deleted in the mouse mutant reeler. Nature 374:719-723. CrossRef Medline

Dobyns WB, Andermann E, Andermann F, Czapansky-Beilman D, Dubeau F, Dulac O, Guerrini R, Hirsch B, Ledbetter DH, Lee NS, Motte J, Pinard JM, Radtke RA, Ross ME, Tampieri D, Walsh CA, Truwit CL (1996) X-linked malformations of neuronal migration. Neurology 47:331-339. CrossRef Medline

Ekşioğlu YZ, Scheffer IE, Cardenas P, Knoll J, DiMario F, Ramsby G, Berg M, Kamuro K, Berkovic SF, Duyk GM, Parisi J, Huttenlocher PR, Walsh CA (1996) Periventricular heterotopia: an X-linked dominant epilepsy locus causing aberrant cerebral cortical development. Neuron 16:77-87. CrossRef Medline

Endo T, Kakeyama M, Uemura Y, Haijima A, Okuno H, Bito H, Tohyama C (2012) Executive function deficits and social-behavioral abnormality in mice exposed to a low dose of dioxin in utero and via lactation. PLoS One 7:e50741. CrossRef Medline

Faizi M, Bader PL, Saw N, Nguyen TV, Beraki S, Wyss-Coray T, Longo FM, Shamloo M (2012) Thyl-hAPP(Lond/Swe+) mouse model of Alzheimer's disease displays broad behavioral deficits in sensorimotor, cognitive and social function. Brain Behav 2:142-154. CrossRef Medline

Felker MV, Walker LM, Sokol DK, Edwards-Brown M, Chang BS (2011) Early cognitive and behavioral problems in children with nodular heterotopia. Epilepsy Behav 22:523-526. CrossRef Medline

Fry AE, Kerr MP, Gibbon F, Turnpenny PD, Hamandi K, Stoodley N, Robertson SP, Pilz DT (2013) Neuropsychiatric disease in patients with periventricular heterotopia. J Neuropsychiatry Clin Neurosci 25:26-31. CrossRef Medline

Gleeson JG, Allen KM, Fox JW, Lamperti ED, Berkovic S, Scheffer I, Cooper EC, Dobyns WB, Minnerath SR, Ross ME, Walsh CA (1998) Doublecor- tin, a brain-specific gene mutated in human X-linked lissencephaly and double cortex syndrome, encodes a putative signaling protein. Cell 92:6372. CrossRef Medline

Goes FS, Willour VL, Zandi PP, Belmonte PL, MacKinnon DF, Mondimore FM, Schweizer B, National Institute of Mental Health Genetics Initiative Bipolar Disorder Consortium, DePaulo JR Jr, Gershon ES, McMahon FJ, Potash JB (2010) Sex-specific association of the Reelin gene with bipolar disorder. Am J Med Genet Neuropsychiatr Genet 153B:549-553. CrossRef Medline

Honda T, Kobayashi K, Mikoshiba K, Nakajima K (2011) Regulation of cortical neuron migration by the Reelin signaling pathway. Neurochem Res 36:1270-1279. CrossRef Medline

Inutsuka A, Inui A, Tabuchi S, Tsunematsu T, Lazarus M, Yamanaka A (2014) Concurrent and robust regulation of feeding behaviors and metabolism by orexin neurons. Neuropharmacology 85:451-460. CrossRef Medline

Ishii K, Nagai T, Hirota Y, Noda M, Nabeshima T, Yamada K, Kubo K, Nakajima K (2015) Reelin has a preventive effect on phencyclidineinduced cognitive and sensory-motor gating deficits. Neurosci Res 96 : 30-36. CrossRef Medline

Kanatani S, Honda T, Aramaki M, Hayashi K, Kubo KI, Ishida M, Tanaka DM, Kawauchi T, Sekine K, Kusuzawa S, Kawasaki T, Hirata T, Tabata H, Uhlén P, Nakajima K (2015) The COUP-TFII/Neuropilin-2 is a molecular switch steering diencephalon-derived GABAergic neurons in the developing mouse brain. Proc Natl Acad Sci U S A, in press.

Kawauchi T, Chihama K, Nishimura YV, Nabeshima Y, Hoshino M (2005) MAP1B phosphorylation is differentially regulated by $\mathrm{Cdk} 5 / \mathrm{p} 35, \mathrm{Cdk} 5 / \mathrm{p} 25$, and JNK. Biochem Biophys Res Commun 331:50-55. CrossRef Medline

Kubo K, Honda T, Tomita K, Sekine K, Ishii K, Uto A, Kobayashi K, Tabata H, Nakajima K (2010) Ectopic Reelin induces neuronal aggregation with a normal birth date-dependent "inside-out" alignment in the developing neocortex. J Neurosci 30:10953-10966. CrossRef Medline

Liu Y, Chen PL, McGrath J, Wolyniec P, Fallin D, Nestadt G, Liang KY, Pulver A, Valle D, Avramopoulos D (2010) Replication of an association of a common variant in the Reelin gene (RELN) with schizophrenia in Ashkenazi Jewish women. Psychiatr Genet 20:184-186. CrossRef Medline

Manent JB, Wang Y, Chang Y, Paramasivam M, LoTurco JJ (2009) Dcx reexpression reduces subcortical band heterotopia and seizure threshold in an animal model of neuronal migration disorder. Nat Med 15:84-90. CrossRef Medline

Maurice T, Hiramatsu M, Itoh J, Kameyama T, Hasegawa T, Nabeshima T (1994) Behavioral evidence for a modulating role of sigma ligands in memory processes: I. Attenuation of dizocilpine (MK-801)-induced amnesia. Brain Res 647:44-56. CrossRef Medline

Miller MW (1985) Cogeneration of retrogradely labeled corticocortical projection and GABA-immunoreactive local circuit neurons in cerebral cortex. Brain Res 355:187-192. Medline

Nagano T, Morikubo S, Sato M (2004) Filamin A and FILIP (Filamin A-Interacting Protein) regulate cell polarity and motility in neocortical subventricular and intermediate zones during radial migration. J Neurosci 24:9648-9657. CrossRef Medline

Nakajima K (2007) Control of tangential/non-radial migration of neurons in the developing cerebral cortex. Neurochem Int 51:121-131. CrossRef Medline

Nakajima K, Mikoshiba K, Miyata T, Kudo C, Ogawa M (1997) Disruption of hippocampal development in vivo by CR-50 mAb against reelin. Proc Natl Acad Sci U S A 94:8196-8201. CrossRef Medline

Niu S, Renfro A, Quattrocchi CC, Sheldon M, D’Arcangelo G (2004) Reelin promotes hippocampal dendrite development through the VLDLR/ ApoER2-Dab1 pathway. Neuron 41:71-84. CrossRef Medline

Niwa H, Yamamura K, Miyazaki J (1991) Efficient selection for highexpression transfectants with a novel eukaryotic vector. Gene 108:193199. CrossRef Medline

Niwa M, Kamiya A, Murai R, Kubo K, Gruber AJ, Tomita K, Lu L, Tomisato S, Jaaro-Peled H, Seshadri S, Hiyama H, Huang B, Kohda K, Noda Y, O’Donnell P, Nakajima K, Sawa A, Nabeshima T (2010) Knockdown of DISC1 by in utero gene transfer disturbs postnatal dopaminergic maturation in the frontal cortex and leads to adult behavioral deficits. Neuron 65:480-489. CrossRef Medline

Nopoulos P, Berg S, Castellenos FX, Delgado A, Andreasen NC, Rapoport JL (2000) Developmental brain anomalies in children with attention-deficit hyperactivity disorder. J Child Neurol 15:102-108. CrossRef Medline 
Ogawa M, Miyata T, Nakajima K, Yagyu K, Seike M, Ikenaka K, Yamamoto H, Mikoshiba K (1995) The reeler gene-associated antigen on CajalRetzius neurons is a crucial molecule for laminar organization of cortical neurons. Neuron 14:899-912. CrossRef Medline

Ohshima T, Ward JM, Huh CG, Longenecker G, Veeranna, Pant HC, Brady RO, Martin LJ, Kulkarni AB (1996) Targeted disruption of the cyclindependent kinase 5 gene results in abnormal corticogenesis, neuronal pathology and perinatal death. Proc Natl Acad Sci U S A 93:11173-11178. CrossRef Medline

Pizoli CE, Jinnah HA, Billingsley ML, Hess EJ (2002) Abnormal cerebellar signaling induces dystonia in mice. J Neurosci 22:7825-7833. Medline

Pujadas L, Gruart A, Bosch C, Delgado L, Teixeira CM, Rossi D, de Lecea L, Martínez A, Delgado-García JM, Soriano E (2010) Reelin regulates postnatal neurogenesis and enhances spine hypertrophy and long-term potentiation. J Neurosci 30:4636-4649. CrossRef Medline

Racine RJ, Gartner JG, Burnham WM (1972) Epileptiform activity and neural plasticity in limbic structures. Brain Res 47:262-268. CrossRef Medline

Sarter M, Bodewitz G, Stephens DN (1988) Attenuation of scopolamineinduced impairment of spontaneous alteration behaviour by antagonist but not inverse agonist and agonist beta-carbolines. Psychopharmacology 94:491-495. CrossRef Medline

Seamans JK, Floresco SB, Phillips AG (1998) D1 receptor modulation of hippocampal-prefrontal cortical circuits integrating spatial memory with executive functions in the rat. J Neurosci 18:1613-1621. Medline

Sekine K, Kubo K, Nakajima K (2014) How does Reelin control neuronal migration and layer formation in the developing mammalian neocortex? Neurosci Res 86:50-58. CrossRef Medline

Shifman S, Johannesson M, Bronstein M, Chen SX, Collier DA, Craddock NJ, Kendler KS, Li T, O’Donovan M, O’Neill FA, Owen MJ, Walsh D, Weinberger DR, Sun C, Flint J, Darvasi A (2008) Genome-wide association identifies a common variant in the reelin gene that increases the risk of schizophrenia only in women. PLoS Genet 4:e28. CrossRef Medline

Sisodiya SM (2004) Malformations of cortical development: burdens and insights from important causes of human epilepsy. Lancet Neurol 3: 29-38. CrossRef Medline

Tabata H, Nakajima K (2001) Efficient in utero gene transfer system to the developing mouse brain using electroporation: visualization of neuronal migration in the developing cortex. Neuroscience 103:865-872. CrossRef Medline

Tabata H, Nakajima K (2008) Labeling embryonic mouse central nervous system cells by in utero electroporation. Dev Growth Differ 50:507-511. CrossRef Medline
Takahashi T, Goto T, Miyama S, Nowakowski RS, Caviness VS Jr (1999) Sequence of neuron origin and neocortical laminar fate: relation to cell cycle of origin in the developing murine cerebral wall. J Neurosci 19: 10357-10371. Medline

Tanaka DH, Nakajima K (2012) Migratory pathways of GABAergic interneurons when they enter the neocortex. Eur J Neurosci 35:1655-1660. CrossRef Medline

Tanaka DH, Yanagida M, Zhu Y, Mikami S, Nagasawa T, Miyazaki J, Yanagawa Y, Obata K, Murakami F (2009) Random walk behavior of migrating cortical interneurons in the marginal zone: time-lapse analysis in flat-mount cortex. J Neurosci 29:1300-1311. CrossRef Medline

Teixeira CM, Martín ED, Sahún I, Masachs N, Pujadas L, Corvelo A, Bosch C, Rossi D, Martinez A, Maldonado R, Dierssen M, Soriano E (2011) Overexpression of Reelin prevents the manifestation of behavioral phenotypes related to schizophrenia and bipolar disorder. Neuropsychopharmacology 36:2395-2405. CrossRef Medline

Wang F, Zhu J, Zhu H, Zhang Q, Lin Z, Hu H (2011) Bidirectional control of social hierarchy by synaptic efficacy in medial prefrontal cortex. Science 334:693-697. CrossRef Medline

Weeber EJ, Beffert U, Jones C, Christian JM, Forster E, Sweatt JD, Herz J (2002) Reelin and ApoE receptors cooperate to enhance hippocampal synaptic plasticity and learning. J Biol Chem 277:39944-39952. CrossRef Medline

Wegiel J, Kuchna I, Nowicki K, Imaki H, Wegiel J,Marchi E, Ma SY, Chauhan A, Chauhan V, Bobrowicz TW, de Leon M, Louis LA, Cohen IL, London E, Brown WT, Wisniewski T (2010) The neuropathology of autism: defects of neurogenesis and neuronal migration, and dysplastic changes. Acta Neuropathol 119:755-770. CrossRef Medline

Weinberger DR, Berman KF, Illowsky BP (1988) Physiological dysfunction of dorsolateral prefrontal cortex in schizophrenia: III. A new cohort and evidence for a monoaminergic mechanism. Arch Gen Psychiatry 45:609_ 615. CrossRef Medline

Won H, Lee HR, Gee HY, Mah W, Kim JI, Lee J, Ha S, Chung C, Jung ES, Cho YS, Park SG, Lee JS, Lee K, Kim D, Bae YC, Kaang BK, Lee MG, Kim E (2012) Autistic-like social behaviour in Shank2-mutant mice improved by restoring NMDA receptor function. Nature 486:261-265. CrossRef Medline

Yozu M, Tabata H, Nakajima K (2004) Birth-date-dependent alignment of GABAergic neurons occurs in a different pattern from that of nonGABAergic neurons in the developing mouse visual cortex. Neurosci Res 49:395-403. CrossRef Medline 